
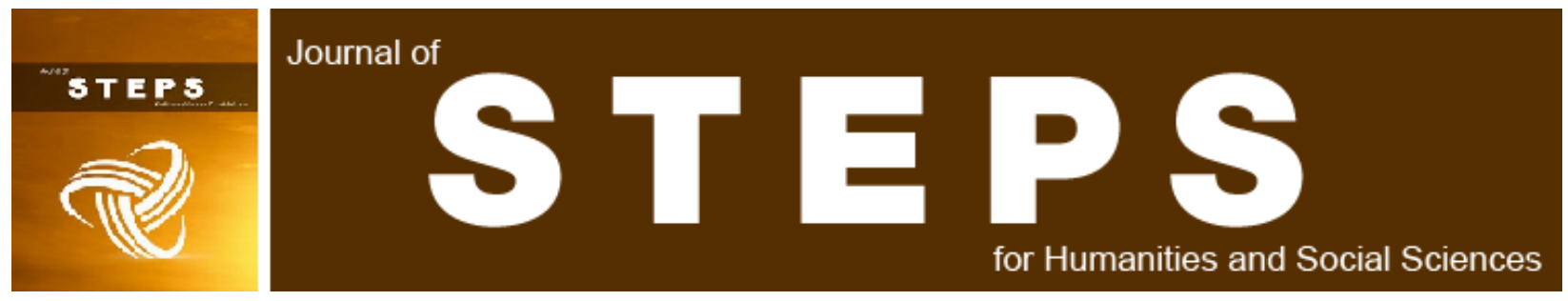

Volume 1 | Issue 1

Article 9

\title{
The effect of spiritual dimensions in creating the epistemological sublime of the products
}

Ali Farhan Al shiply

University of Technology, Iraq, Ali_dirwesh@yahoo.com

Abbas Ali Al Greiza

University of Technology, Iraq

Follow this and additional works at: https://www.steps-journal.com/jshss

Part of the Education Commons

\section{Recommended Citation}

Al shiply, Ali Farhan and Al Greiza, Abbas Ali (2022) "The effect of spiritual dimensions in creating the epistemological sublime of the products," Journal of STEPS for Humanities and Social Sciences: Vol. 1 : Iss. 1 , Article 9.

Available at: https://doi.org/10.55384/2790-4237.1005

This Original Study is brought to you for free and open access by Journal of STEPS for Humanities and Social Sciences (STEPS). It has been accepted for inclusion in Journal of STEPS for Humanities and Social Sciences by an authorized editor of Journal of STEPS for Humanities and Social Sciences (STEPS). 


\section{اثر الابعاد الروحية في خلق السمو الابستمولوجي العقائدي للنتاجات}

علي فرحان درويش الثبلي* عباس علي حمزة الكريزة

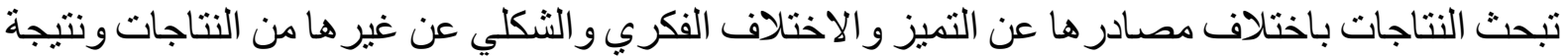

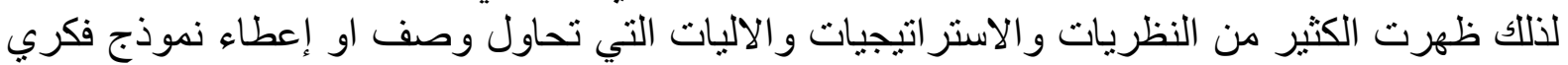

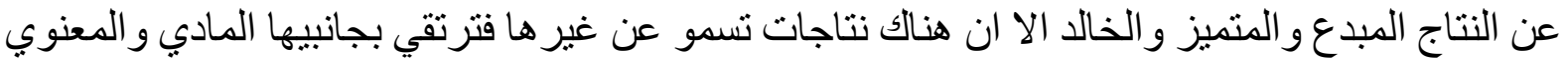

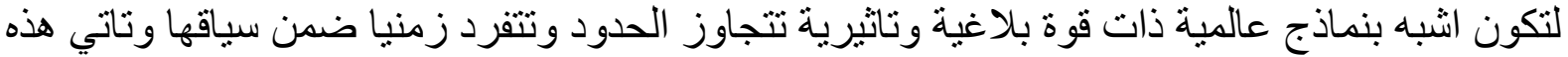

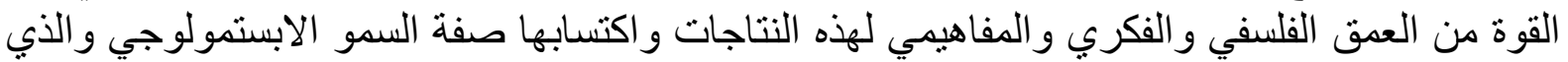

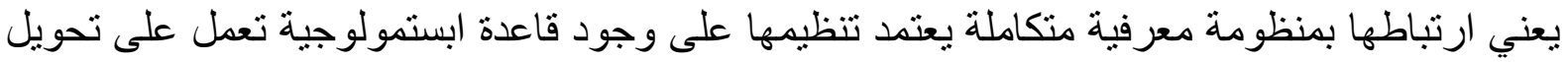

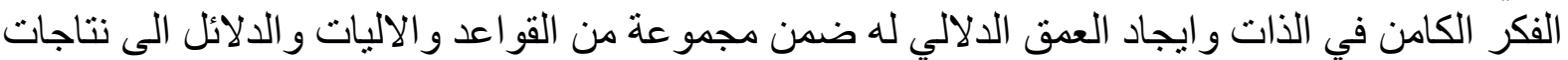

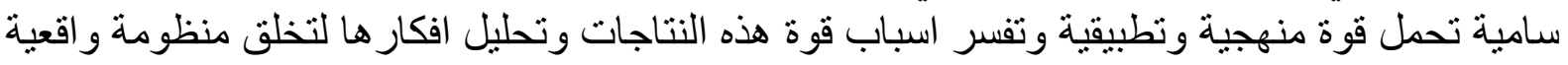

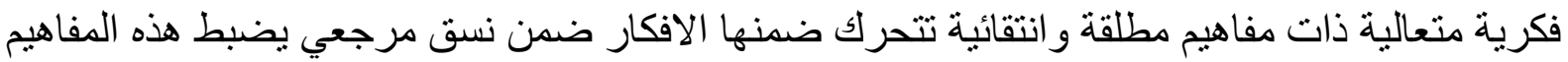

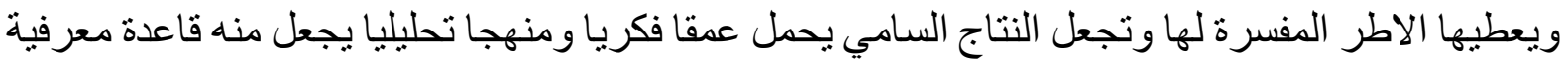

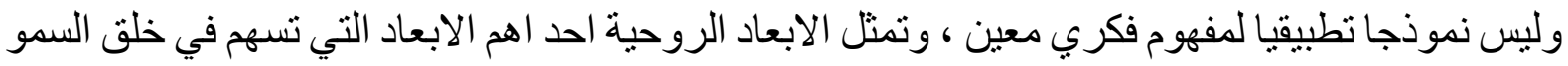

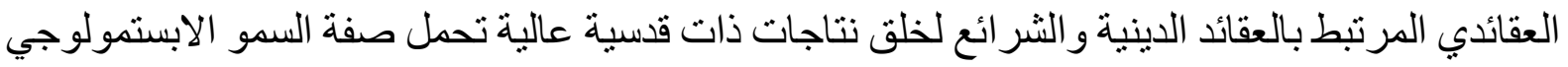

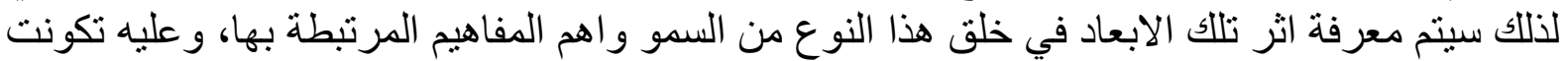

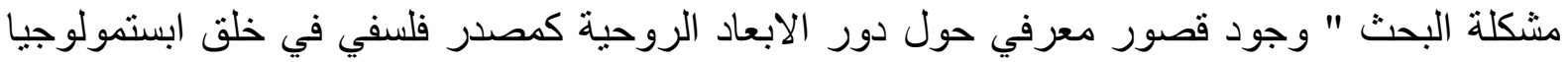

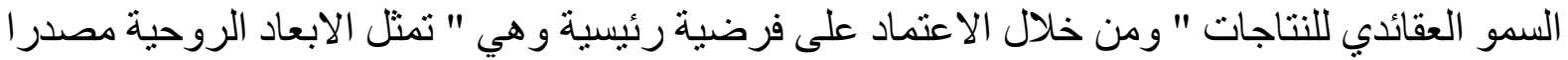
فلسفيا أساسيا في استثارة القيم القسية و العقائدية اللامتتاهية في منظومة اللئية السمو الابستمولوجي".

كلمات مفتاحية: الابعاد الروحية ، السمو ، السمو الابستمولوجي ، السمو العقائدي، القيم القسية.

* * الهنسة المعمارية، الجامعة التكنولوجية، العراق. Ali_dirwesh@yahoo.com 


\title{
The effect of spiritual dimensions in creating the epistemological sublime of the products
}

Ali Farhan Dirwesh Al Shiply, Architecture Department, University of Technology, Iraq.

Abbas Ali Hamza Al Greiza, Architecture Department, University of Technology, Iraq.

\begin{abstract}
The products, with their different sources, search for excellence and intellectual and formal differences from other products. As a result, many theories, strategies and mechanisms have emerged that attempt to describe or give an intellectual model for the creative, distinguished and immortal product. However, there are products that transcend others, elevating their material and moral sides to be more like global models with strength. Rhetorical and impactful that transcends borders and is unique in time within its context. This power comes from the philosophical, intellectual and conceptual depth of these products and their acquisition of the epistemological transcendence, which means their connection to an integrated knowledge system whose organization depends on the existence of an epistemological base that works to transform the thought inherent in the self and find its semantic depth within a set of rules and mechanisms Evidence for sublime products carry methodological and applied force and explain the reasons for the strength of these products and analyze their ideas to create a realistic, transcendent intellectual system with absolute and selective concepts within which ideas move within a reference system that controls these concepts and gives them the frameworks interpreting them. An applied model for a specific intellectual concept, and the dimensions are represented Spirituality is one of the most important dimensions that contribute to the creation of ideological transcendence related to religious beliefs and laws to create products of high sanctity bearing the character of epistemological transcendence. The role of the spiritual dimensions as a philosophical source in creating the epistemology of the doctrinal transcendence of the products" and by relying on a main hypothesis, which is "the spiritual dimensions represent a basic philosophical source in provoking the endless sacred and ideological values in the system of epistemological transcendence".
\end{abstract}

Keywords: spiritual dimensions, sublime, epistemological transcendence, ideological transcendence, sacred values. 
نظر الما تشكله الابعاد الروحية من أهمية في حقل العمارة وخلق نتاجات ذات حضور زماني ومكاني دائم

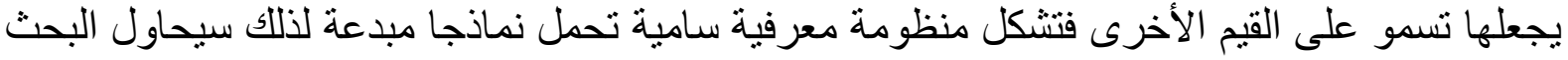
تقصي و استكثاف هذه المنظومة الخاصة بتلك النتاجات التي تحمل صفة السمو العقائدي اليقيني من خلال

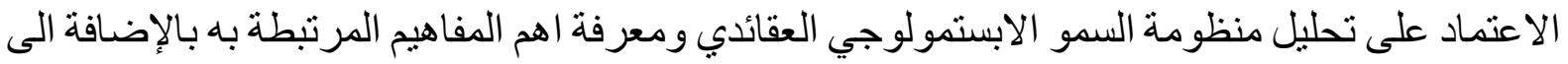
كثف مستويات و علاقات وصيغ توظيف تللك المفاهيم في النتاجات و الاجابة عن مشكلة البحث التهي التي تم

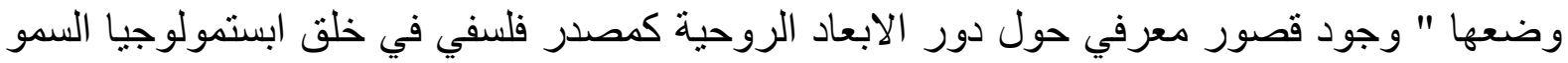

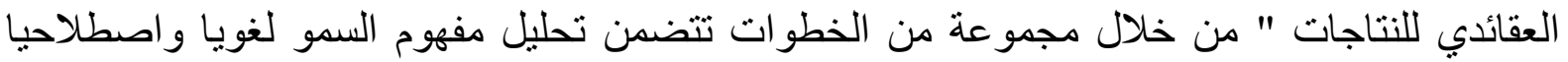

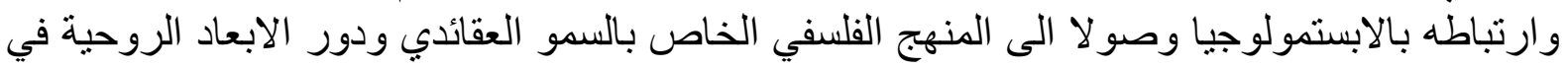
خلق النتاجات التي تتصف بهذا النوع من السمو وتوضيح ارتباطاته الفلسفية و المفاهيمية والتطبيقية و الخوض في اليات توظيفه على المستوبين الفكري و التطبيقي لحل المشكلة البحثية

الابعاد الروحية

و هي المضامين الروحية العليا التي تنظم حياة الناس الدينية و الدنيوية وتكون في حالة استقرار تام عبر الزمن مؤثرة في الفكر الإنساني والذي يعطي بعدا متجليا وساميا في النتاج كون الابعاد الروحية تمثنل

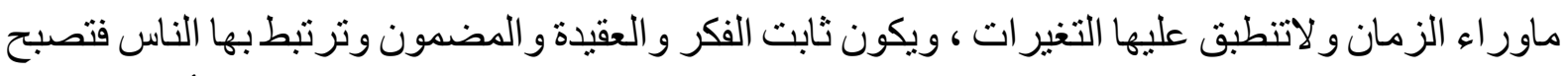

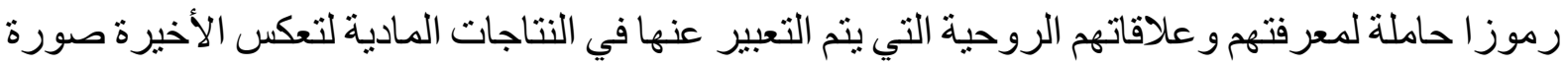
الروح والهيبة والتجلي بصورة متكاملة ، وترتبط الابعاد الروحية بالجوانب الميتافيزيقية و التي تعتبر

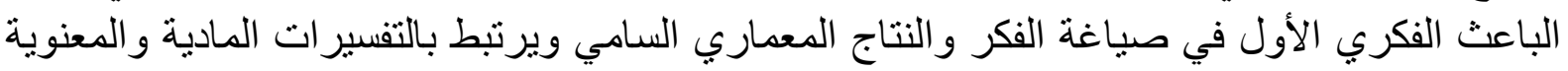

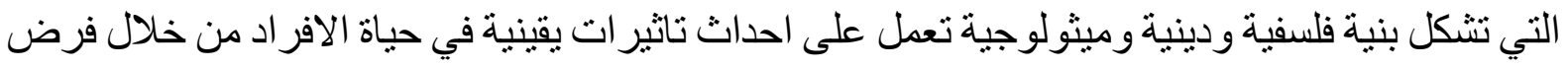
معتقات وفلسفات ورؤى فكرية تحل محل العقائد والاساطير التي تحمل قيم جدلية متغيرة ، وتندر ج الابعاد

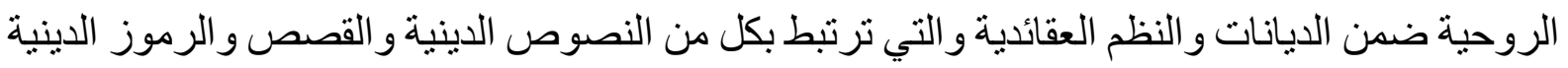

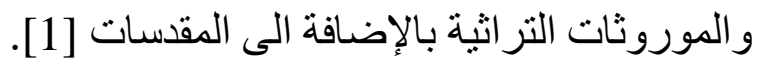

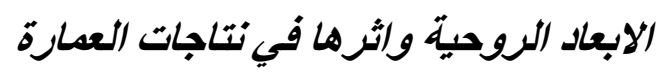

تثير الابعاد الروحية العديد من القيم والمفاهيم التي تسهم في إعطاء العمارة بعدا رمزيا عاليا يؤثر في

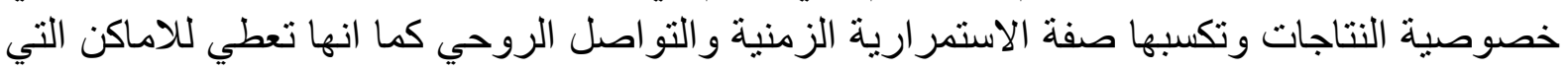
تتو اجد فيها هوية ثقافية ورمزية عالية ، و هناك مجمو عة من القيم التي تثير ها الابعاد الروحية في النتاجات

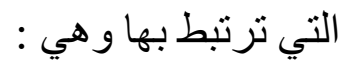
ـ استمر ارية الترابط الروحي وهي التي تهي تعطي الإحساس بقوة تشكيل المكان والحصول على التقديس

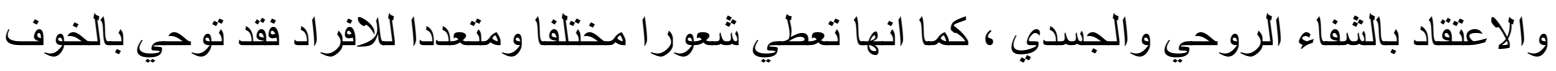
او بالر هبة او الثراء النفسي او السكينة او القيام بفعل معين وكما تمثل صلة الانسان بربه وسر الثعور

$$
\text { بالاستقرار وفهم الذات }
$$

ـ التجلي الروحي والتي تعني الخصائص الجوهرية للعنصر والتي ترنبط بحضوره التام محافظا على

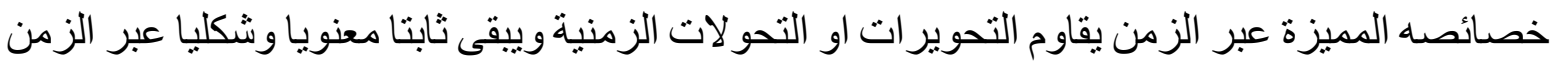

ـ الرمزية وتمثل إثارة لفكرة متبناة من نمط معين لتعبر عن هيكل اجتماعي او ثقافي او ديني وهي صفة

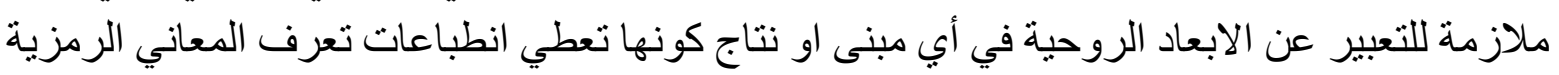
المطلوبة في نتاج معين 
ـ تعزيز الانتماء المكاني ويرتبط هذ المفهوم بالذاكرة الجمعية ويتكون من خلال الإحساس بالتجربة و انثاء

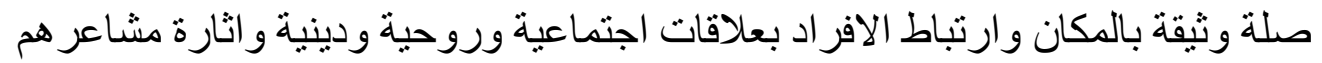

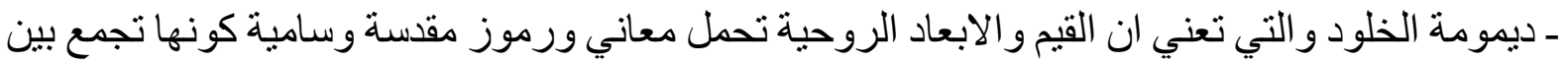

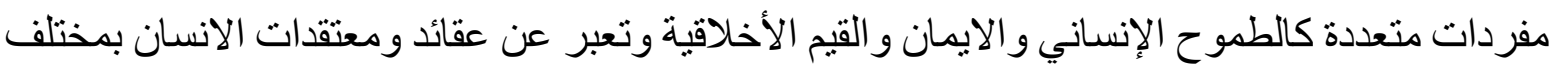

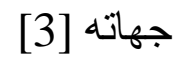

يتبين مما سبق أعلاه ان البعد الروحي يؤثر وبشكل كبير في نتاجات العمارة فهو يكسب النتاجات عمقا

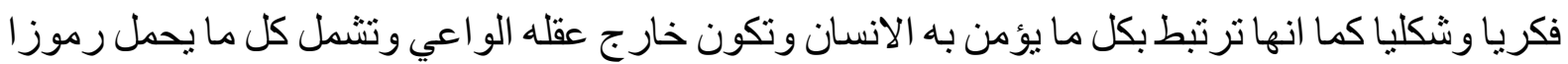

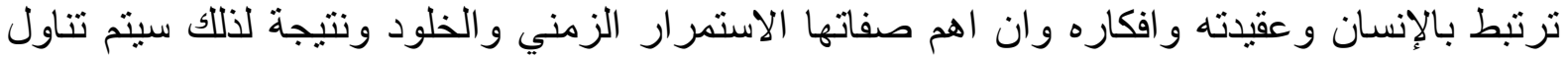

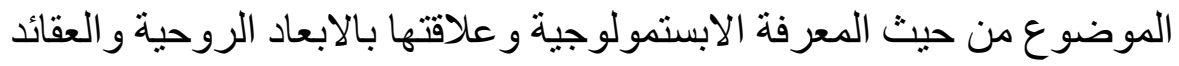

تعريف الابستمولوجيا

هي خطاب حول العلم لا يرمي الى بناء نظرية عامة و إنما هو تحليل للأنتاج العلمي بمر اعاة الطبيعة

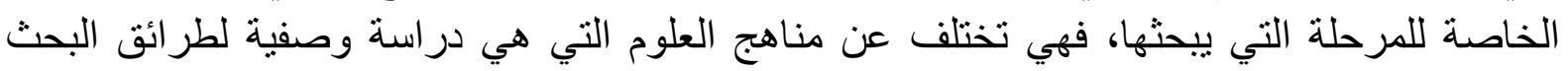

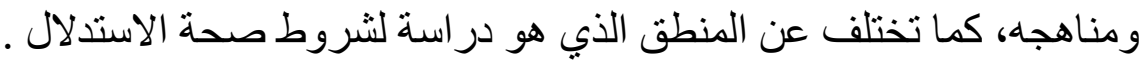
علاقة الابستهولوجيا بالعقائد

ترتبط الابستمولوجيا بالمنطق الكوني التوحيدي فالمنهج الإبستمولوجي العقائدي يقوم بتركيب المبهم من الإني

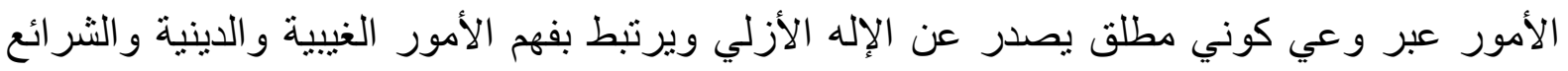

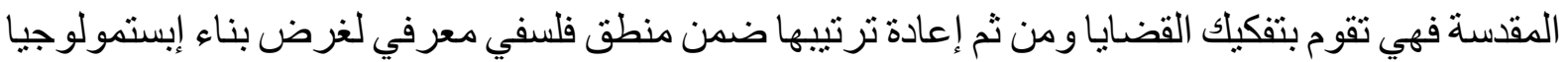

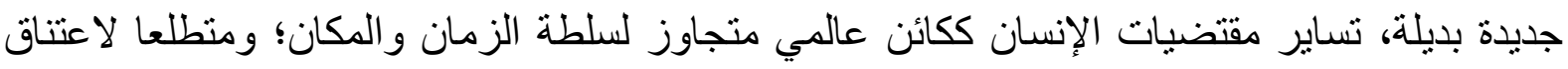

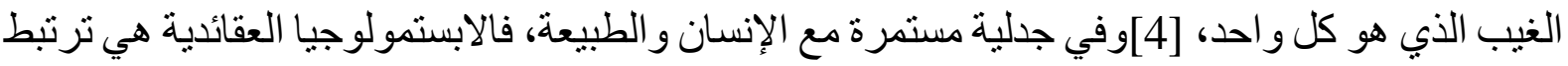

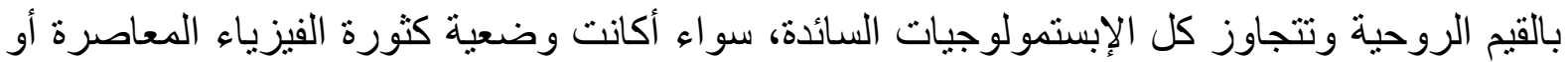

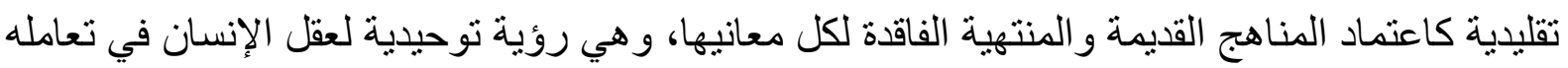

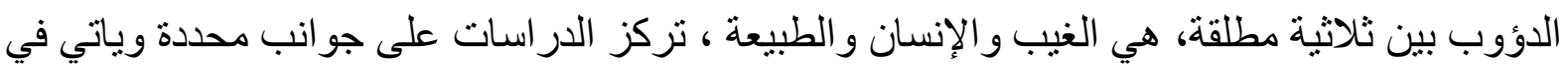

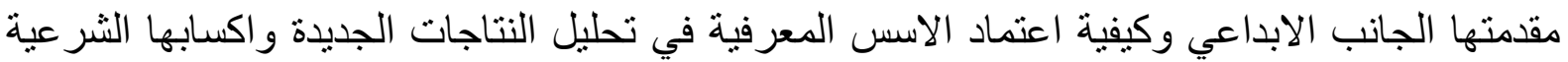

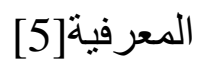
يتبين مما تقدم ان الابستمولوجيا ترتبط بمحاكاة القيم الروحية والتي ترتبط بمفاهيم العقائد والثريعة

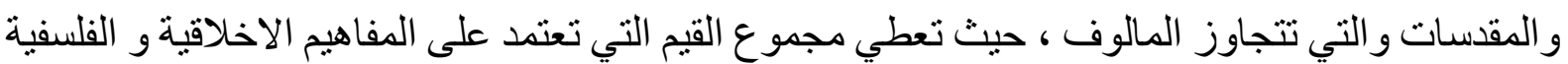

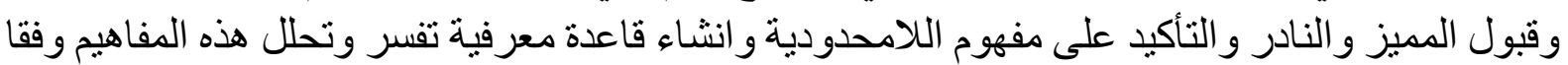
لتلاك القاعدة وتبين ارتباطاتها وحدود تأثنير ها والنا علاقة الابستمولوجيا بالععارة

تركز الابستمولوجيا على الابعاد الفكرية و انعكاسها على النتاجات في العمارة التي تتقصى المشاكل وحلها

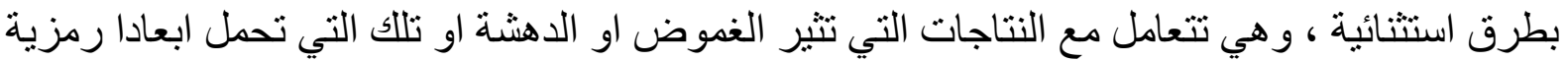

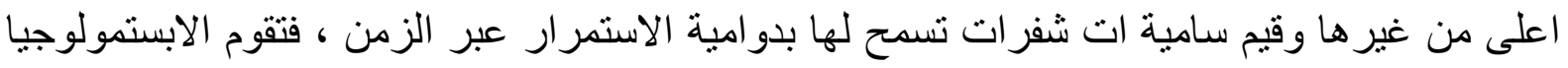

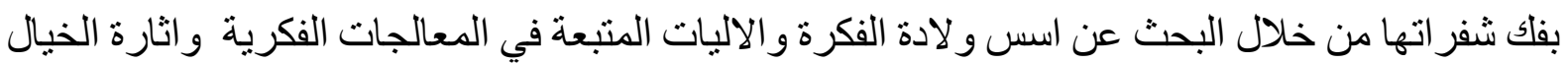

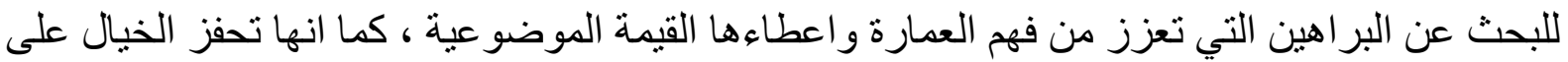

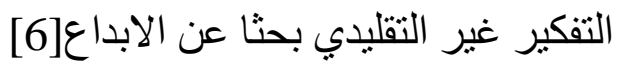




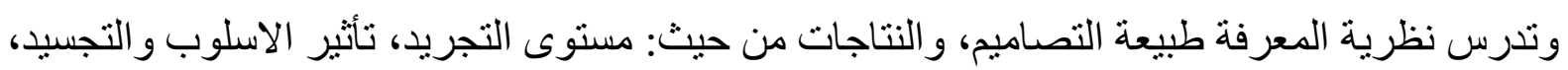

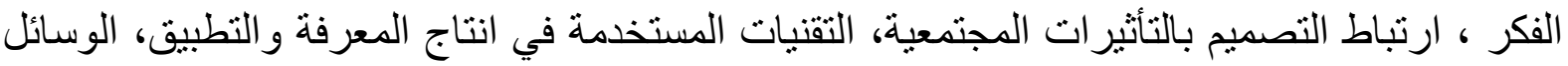

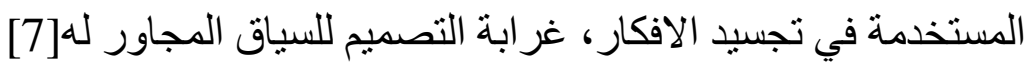

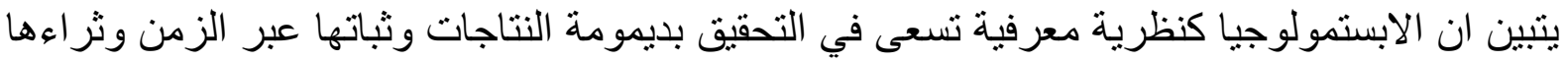

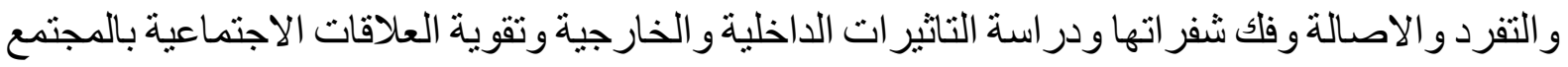

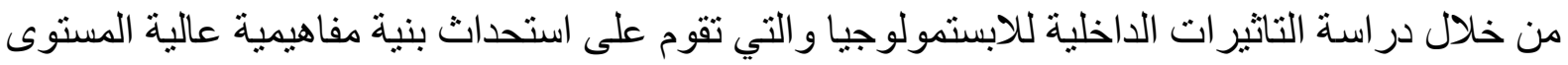

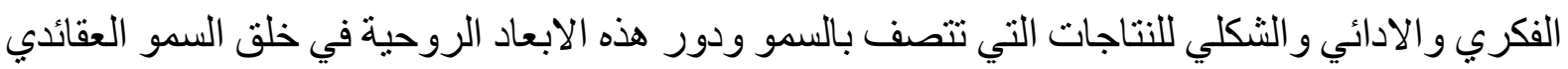

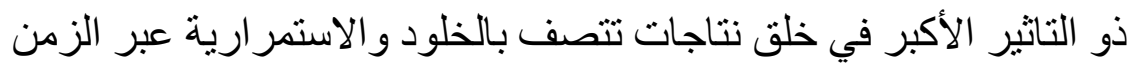

\section{تعريف السمو لغويا}

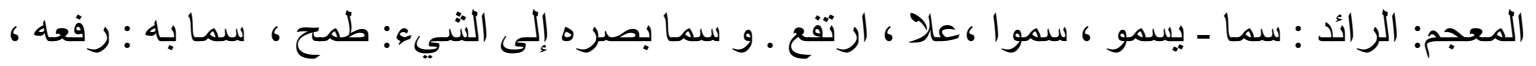

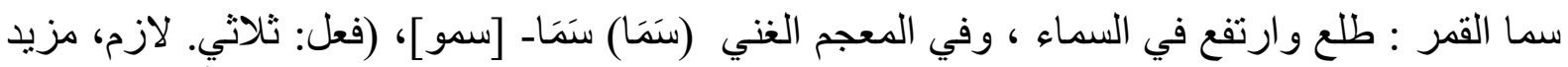

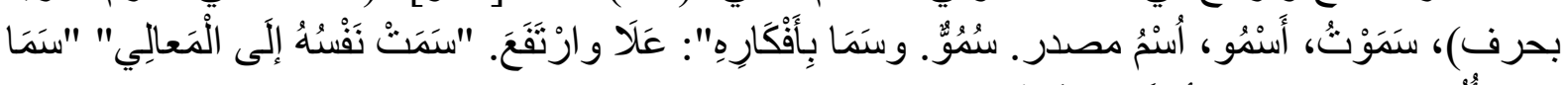

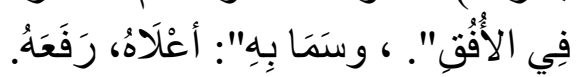

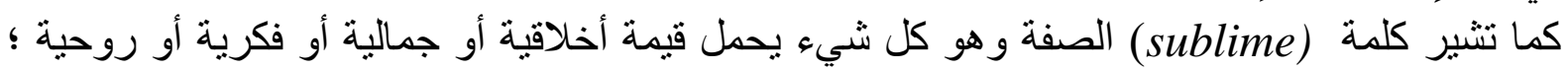

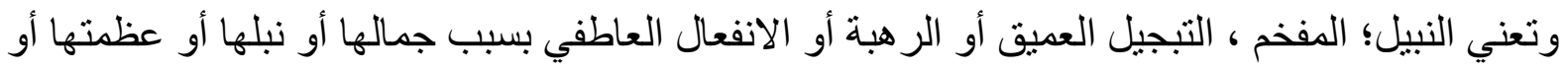

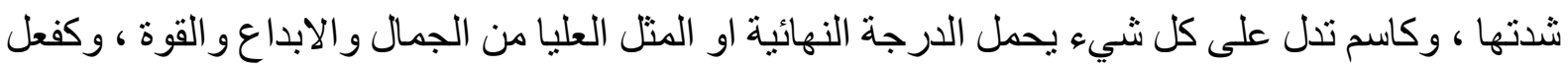

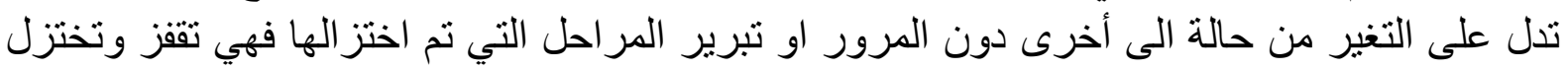

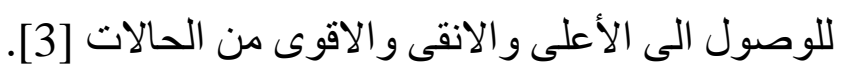
تعريف السمو اصطلاحيا

ويشير مصطلح السمو الى الصفة المميزة المرتبطة بالنو احي الوجدانية والعبقرية المبدعة و البلاغة ،تاتي فئي

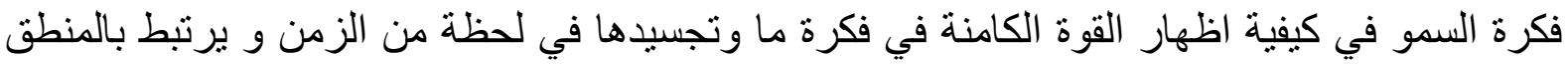

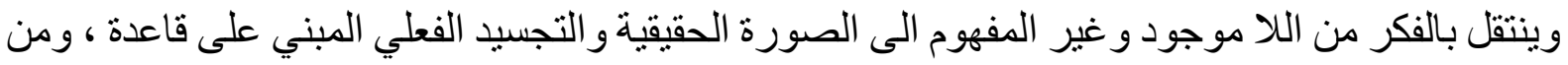

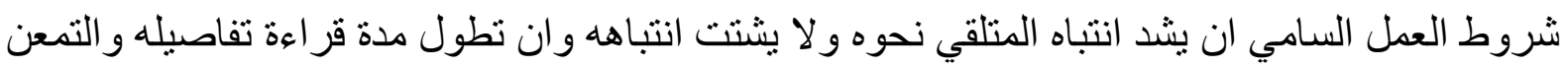

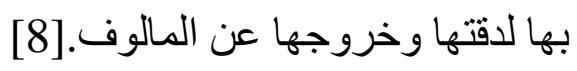

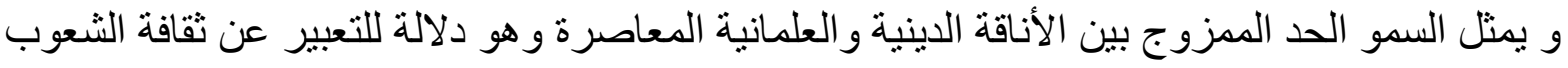

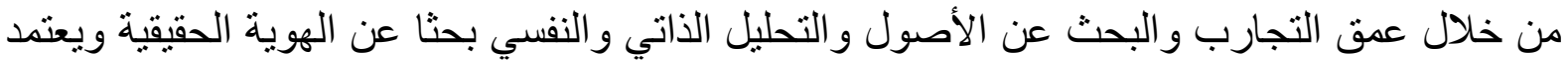

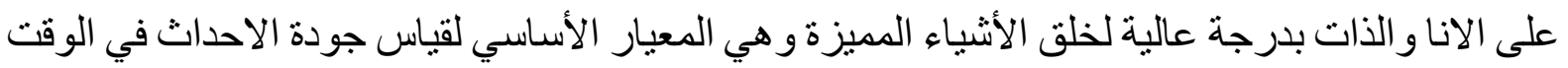

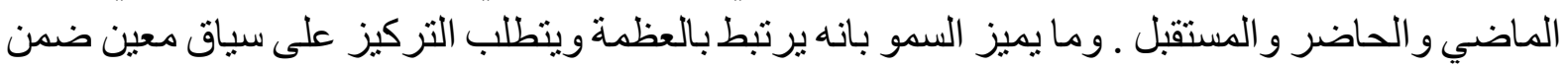

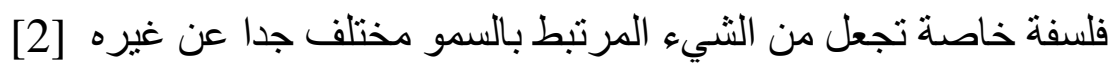

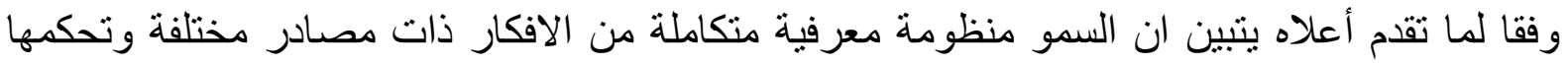

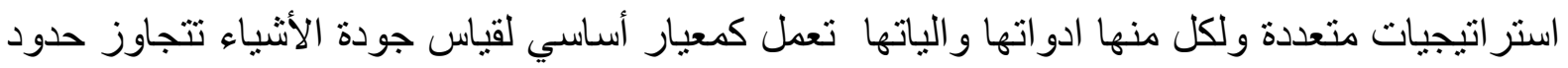

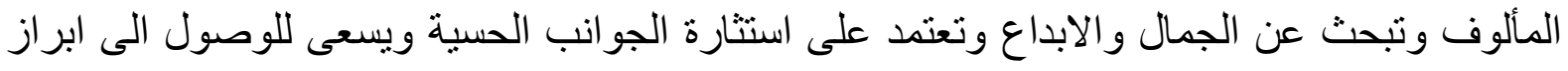

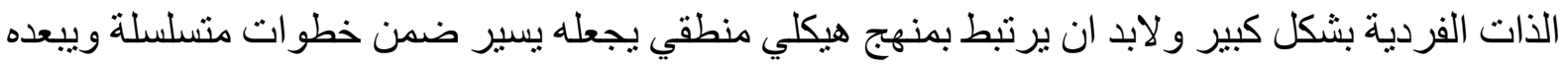

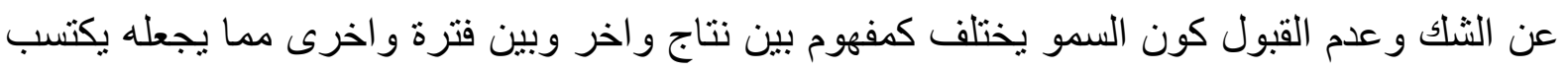
مجمو عة من المفاهيم الحضارية المختلفة التي تندرج ضمن قاعدة السيون السمو المنهجية والمعرفي. 


\section{السدو في الفلسفة}

يرتبط السمو بالنتاجات المختلفة المرتبطة بمفاهيم الحياة و العالم و التي تمتلك كل منها فلسفة معينة ويكون

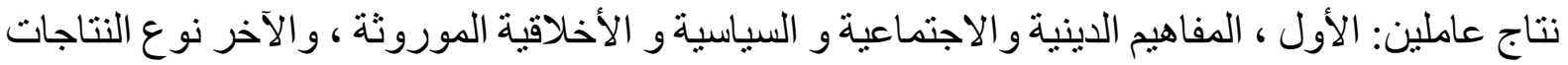
المرتبطة بالحقائق العلمية ، وما يميز فلسفة السمو عن غير ها هو الجمع بين اللاهوت و والعلم وتنكوين

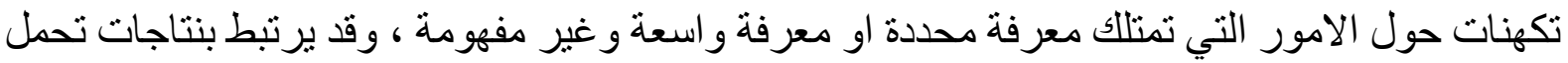
تكهنات مخفية من الصعب الوصول اليها او اكتشافها ، [9]مع ميوله لارتباط بالعلم الذي يميل الى تمييز العقل البشري في الادر الك والحسابات المنطقية و قد ينتمي إلى اللاهوت. فهو يجمع بين العقل و المادة ،

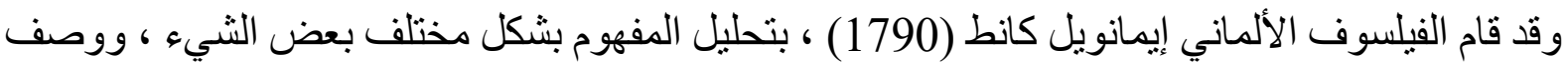

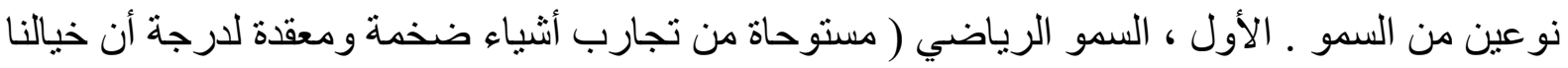

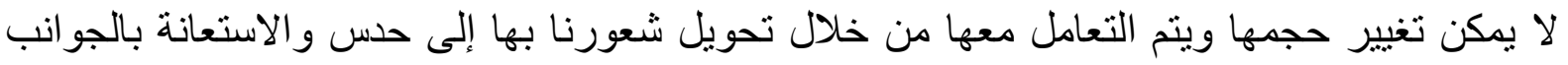
الروحية و الاستدلالية لادر اكها (مثل كنيسة القديس بطرس في روما أو الكون المرصع بالنجوم). و والثاني هو السمو الديناميكي ، يتألف من تجارب لأشياء تمتلك قدرة وقوة عظيمة تسببب الرهبة ورئ والخوف كونها

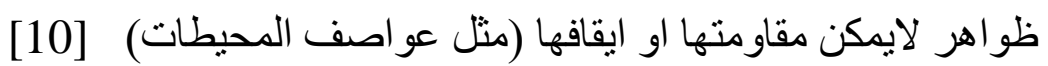
السمو العقائدي

يثنير السمو العقائدي الى كل ماهو مفارق ومتعالي لحياة الناس الدنيوية وهو كل شيء يعتبر احتر امهو اجب

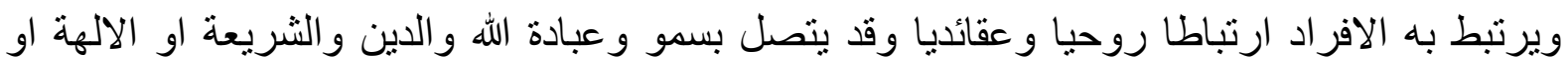

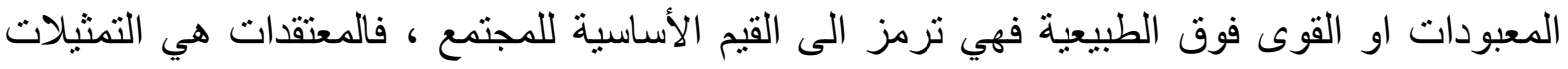
المرتبطة بالأشياء المقدسة وترتبط بنسق معين من الطقوس ضمن اطر معينة تختلف من وجهة الى أخرى ،

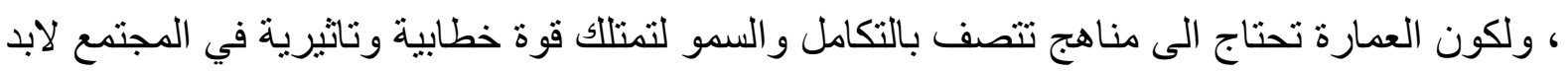
ان يكون النتاج حاملا لاحد المفاهيم الفكرية المرتبطة باساليب عالية البلاغة لاحد المفاهيم او يعيد

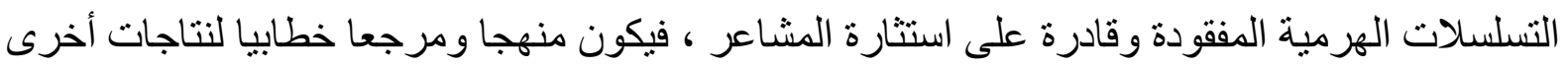

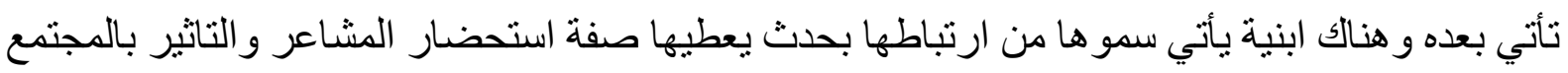

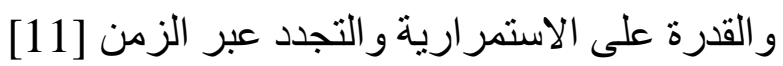

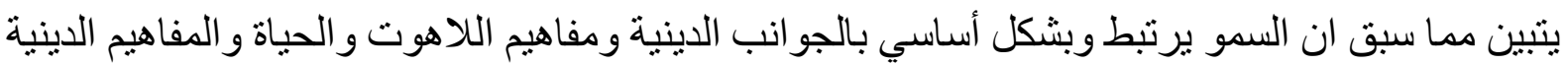
و التي تمثل بمجمو عها عقائد مرتبط بحقائق ويقينيات مختلفة و عندما ترتبط هذه القيم بالنتاجات فانها تمنحها

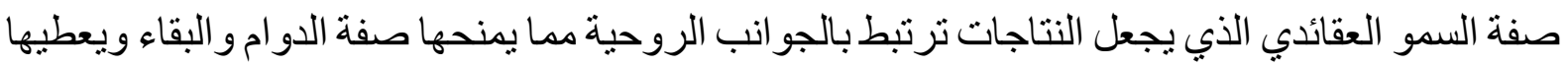

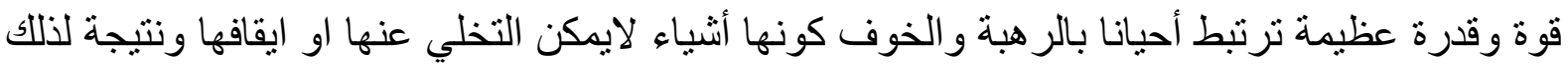
سيتم توضيح السمو الابستمولوجي ودور الابعاد الروحية في خلق هذا النوع من السمو الدر اسات السابقة

سيتم تتاول مجموعة من الدراسات التي تتناول دور الابعاد الروحية في خلق السمو الابستمولوجي

\section{دراسة دكروب بعنوان الاثثروبوليوجيا والذ/كرة والمعاش سنتة 1984}

تهنم هذه الدر اسة بالميتافيزيقيا واهميتها في التأثير على نتاجات العمارة و الثعور التلقائي للأفر اد لتلك النتاجات ومدى ارتباطهم بها ، فهي تكون كأنساق ثقافية تعطي دلالات ومعاني وتجعل من هذه هذه النتاجات

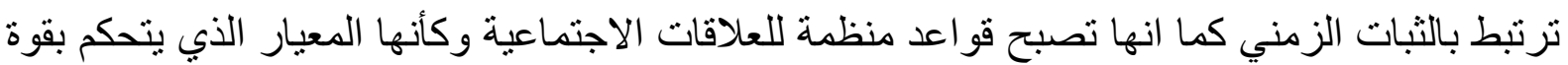

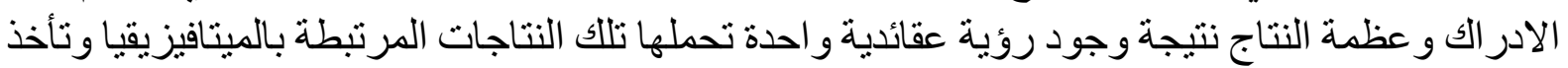
هذه النتاجات صفة الثبات وتزداد قوتها كلما تطور الزمن وتر اكمت الاحداث وبذللك تصبح معبرة عن خبر ات أجيال متو اصلة تعطي رؤية موحدة للوجود و الحياة وتثير الى الاستمر ارية كنتيجة مباشرة للثبات 
ورصانة المفاهيم الميتافيزيقبة والمعتقدات المرتبطة بهاوبذلك فان هذه النتاجات صساغت التشكيل المعماري

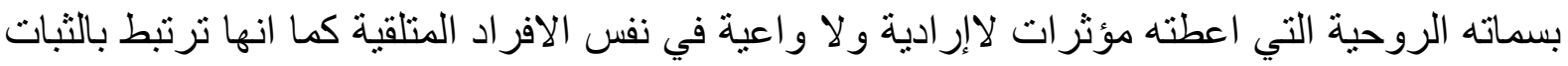

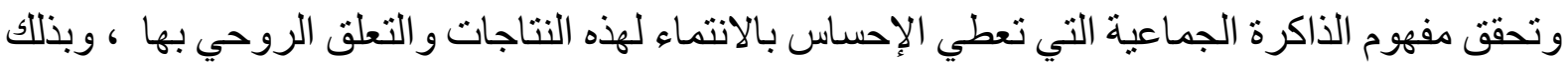

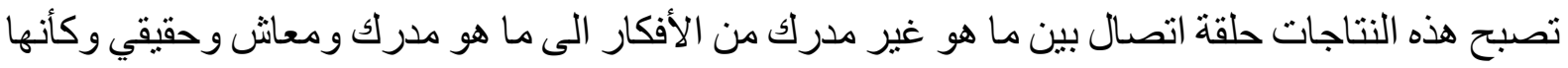
وسائط تعبيرية ثقافية وجمالية تتجسد في هيئة اشكال رمزية تعتبر شاهدا او مؤشر ا زمنيا على رئ رصانتها

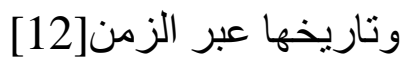
يتبين مما ذكر أعلاه ان الدراسة وضحت أهمية الابعاد الروحية في خلق نتاجات تتصف بالسمو وهذه

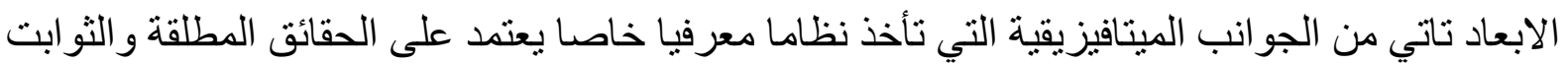

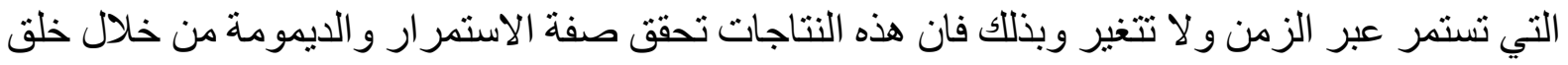

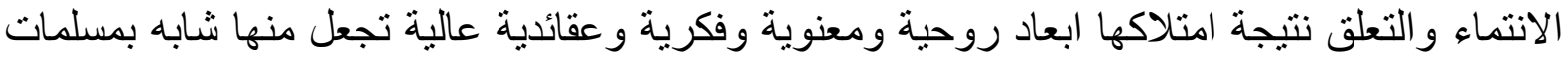
تسمو فوق النتاجات الأخرى وتعلو لتكون قو اعد منظمة ومعيار للحكم نتيجة الرؤى العقائدية التي تحملها دراسة Harreis بعنوان The Ethical function of Architecture سنة 1997

تتناول الدراسة الابعاد الروحية وتاثيرها في سمو النتاجات من حيث اعتماده على المفاهيم

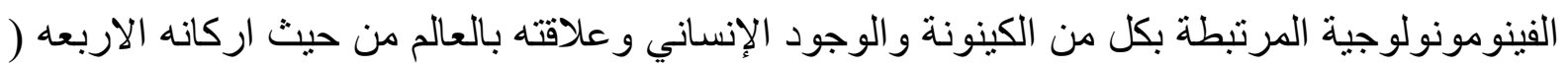

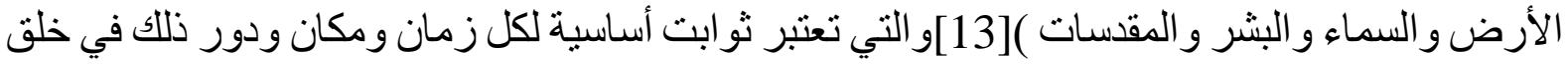
نتاجات تتصف بالسمو من حيث إمكانية استمر اريتها عبر الزمن وارتباطها بصفة النظام الكوني وهي اللازمنية ومو اجهة رهاب الزمن الذي تعاني منه الكثير من نتاجات العمارة ويتناول المباني المقدسة كمثال

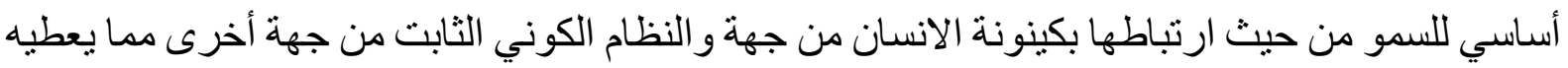

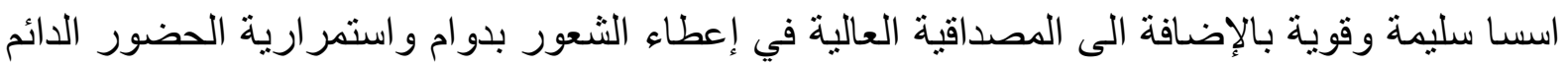

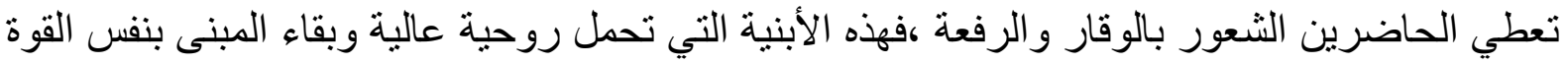
المادية و المعنوية دليل على بقاء روحه وحضوره في الذاكرة الجمعية للافر اد مما يدل على سموه و امتلاكه صفة الفردانية والتي هي جزء من النظام الكوني والتي ترتبط بالإنسان من حيث ان كل شخص التص له له حضور

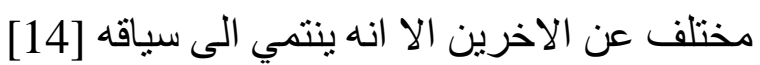
يتبين مما ذكر أعلاه ان الدراسة اعتمدت المفاهيم الفينومينولوجية كمصدر أساسي لخلق نتاجات سامية

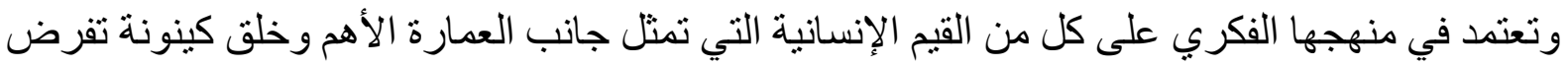

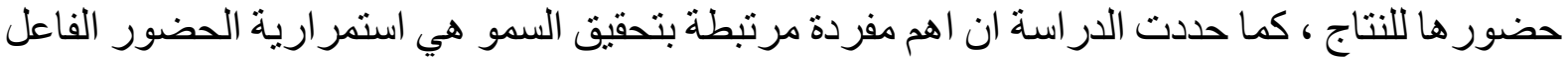
عبر الزمن بنفس القوة والاهمية كاهية

\section{دراستة The Holiness of Jerusalem: Asset or Burden بنتوان Karen Armstrong سنة}

1998

تشير الدر اسة الى السمو من حيث ارتباطه بالبعد اللاهوتي والقداسة الذي يعطي المكان ككل تفردا

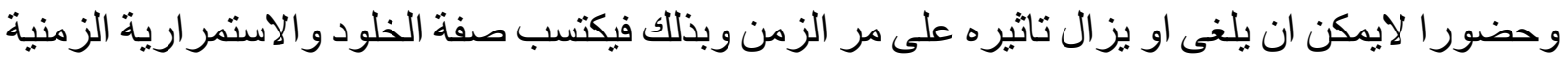

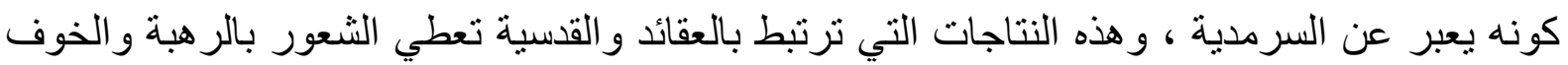

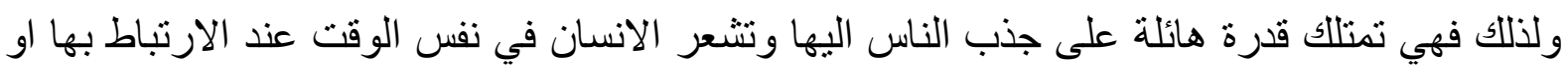

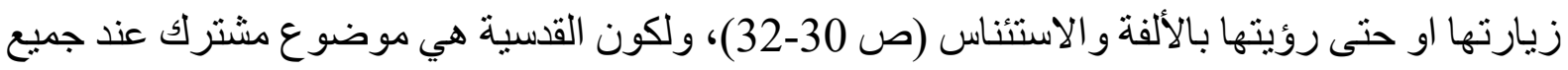

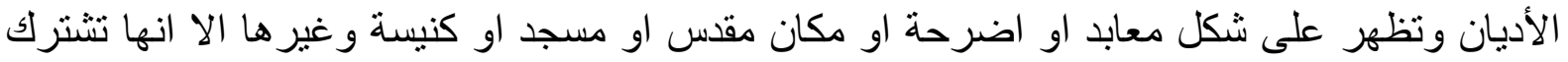

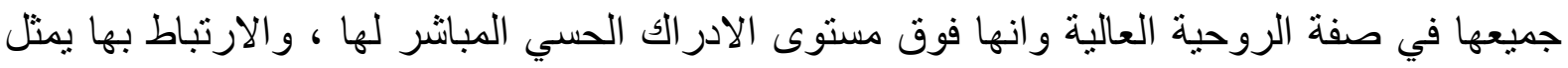

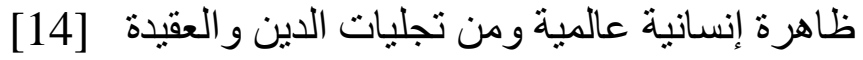


يتبين مما سبق أعلاه ان الدراسة أعطت البعد اللاهوتي والبعد المقدس أهمية كبيرة في كونه احد المصادر

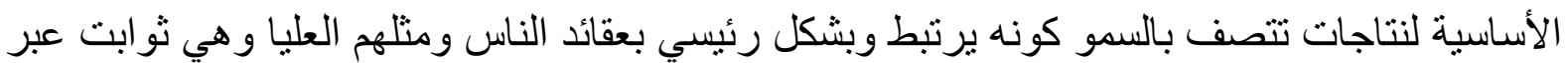

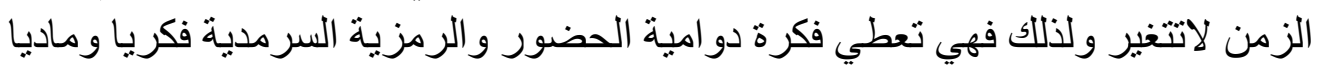

\section{دراسة Brad Olsen بغوان Sacred Places Around the World,108Destinations سنة ونكة}

2004

تتناول الدراسة مفهوم المكان السامي والتي تحددها بانها تللك الأماكن التي تكون لديها خصائص

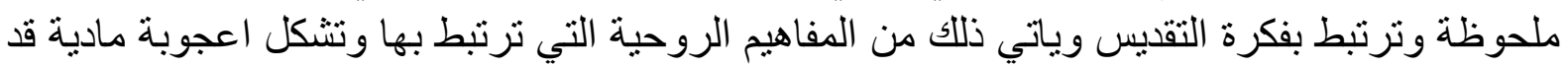

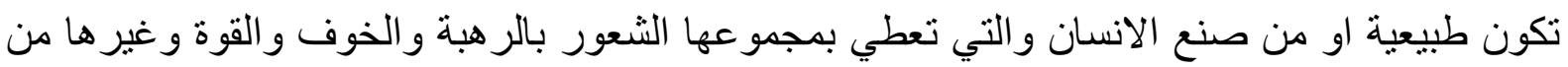

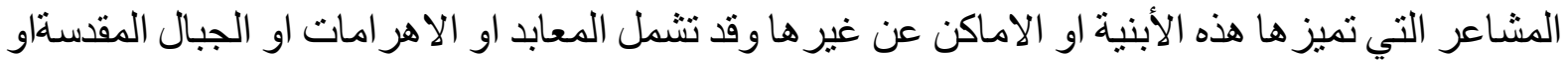

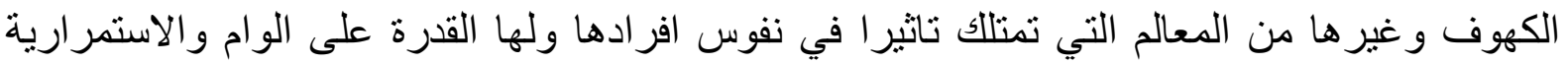

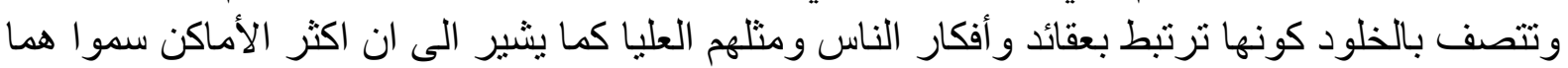

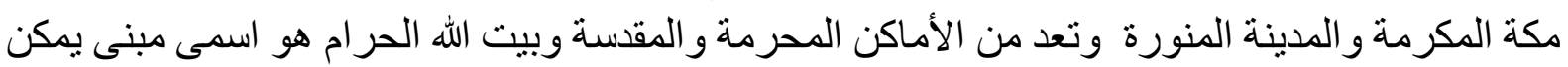

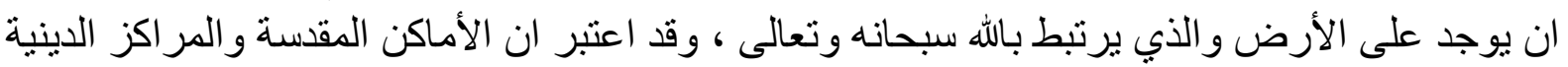

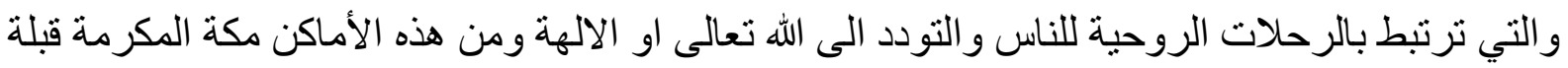

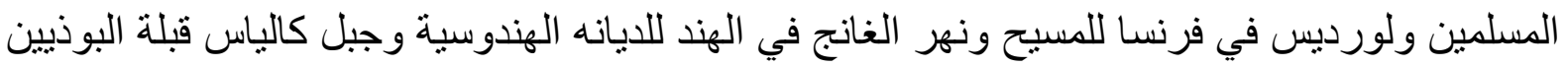

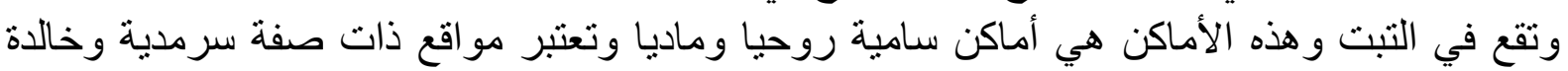

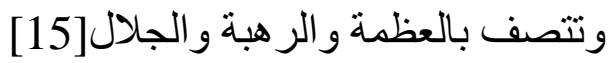

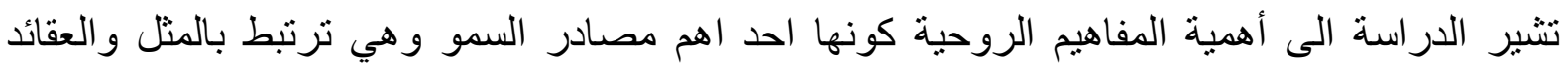

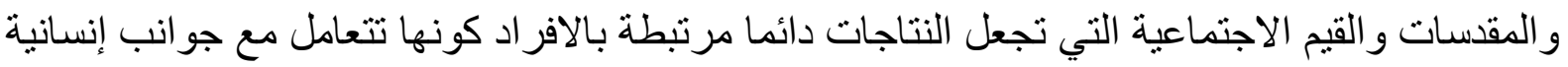

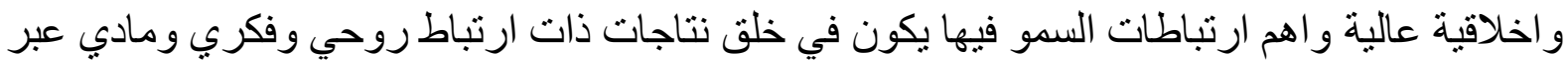

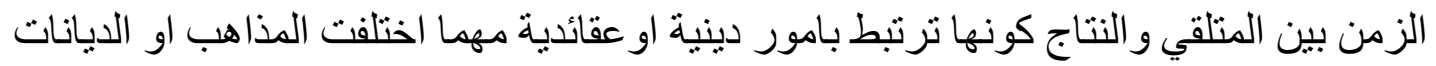

دراسة سلمان وحمبي، بغنوان الخيال الأخلاقي في العمارة سنة بنة 2018

تتناول الدر اسة الابعاد الروحية و المرتبطة بمفهوم الخيال الأخلاقي و التعامل مع الأطر الأخلاقية لانتاج

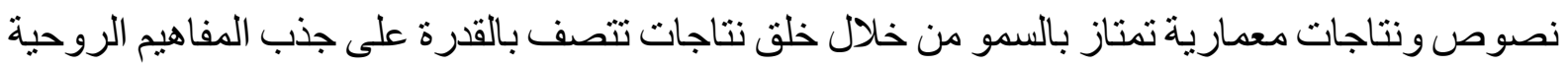
والحسية التي تعزز من انتماء الافر اد اليها وقد تكون من خلال تلال تفعيل الابعاد الروحية لعقائد مجتمعية موروثة او عادات وتقاليد خاصة التئة

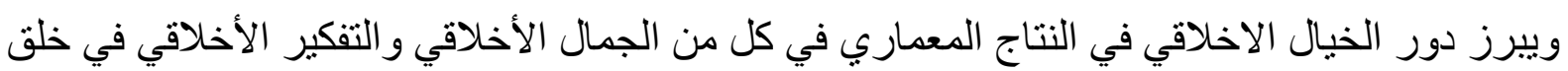

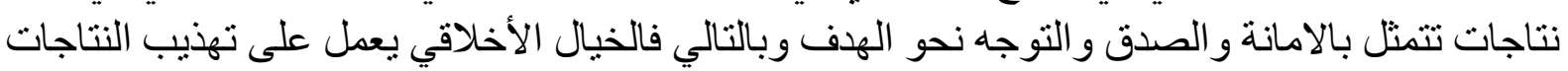

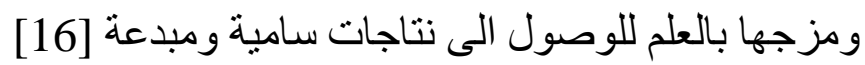


ابرزت الدر اسات السابقة جو انب متعددة للابعاد الروحية المرتبطة بخلق سمو ابستمولوجي يقوم على تفعيل العقائد في النتاجات وقد تمحورت هذه الجو انب حول مجموعة من المفردات و مبادئ السمو الابستمولوجي لوني العقائدي تعطي النتاج السامي الثرعية والقوة و تؤسس لاساليب بلاغية ويمكن ان يتم وضع نموذج فكري للسمو الابستمولوجي العقائدي (الثكل 1)

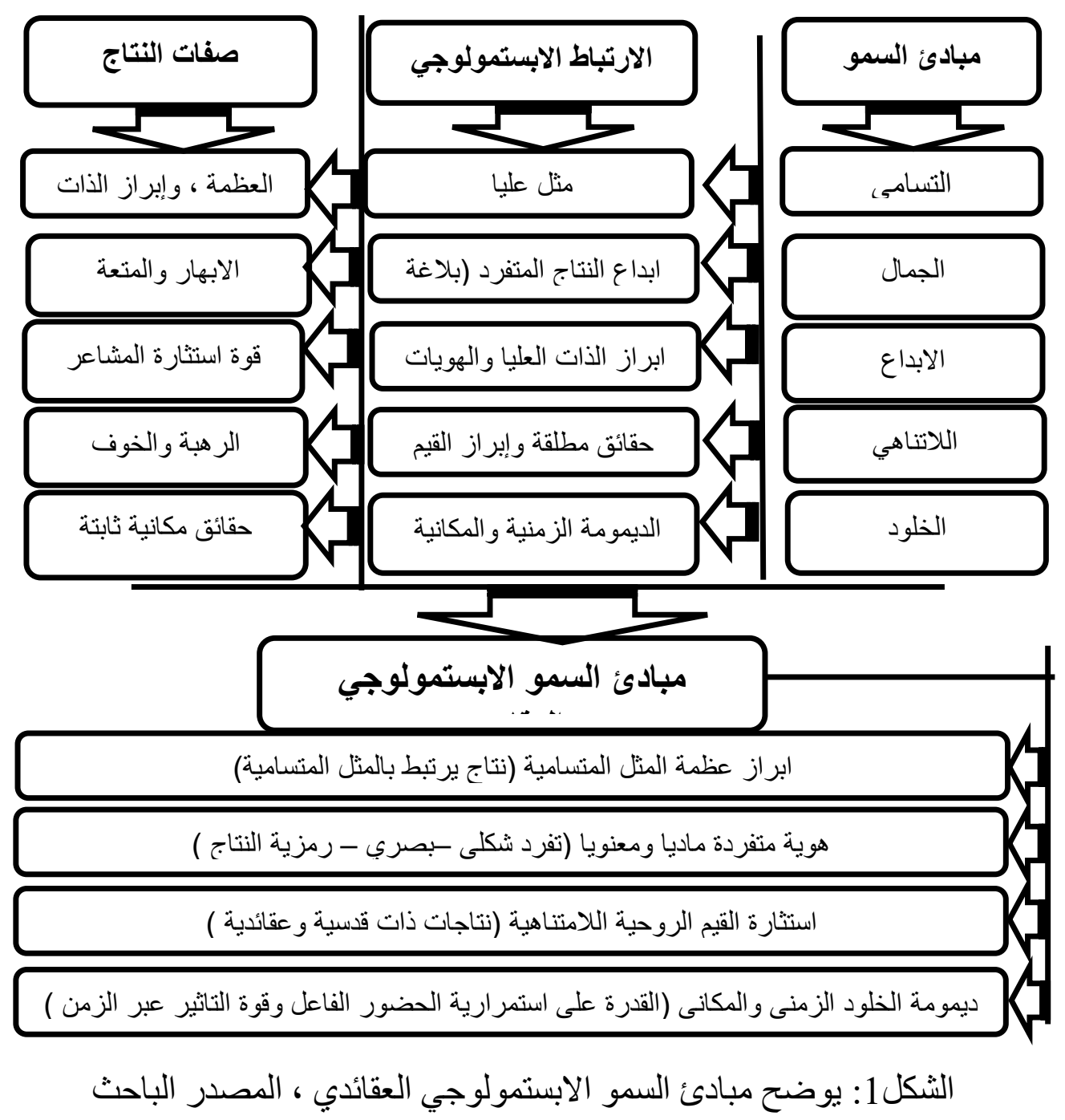

الجانب التطبيقي

سيتم اختيار مجمو عة من النتاجات المحلية التي تحمل جوانب روحية وتعطي سمو عقائدي وتتمثل بكل من 1-جامع ام الطبول في بغداد 2- نصب الثهيد في بغداد 3- كنيسة سيدة النجاة في بغداد وصف قيم السمو في النتاجات المختارة جامع ام الطبول في بغد/د

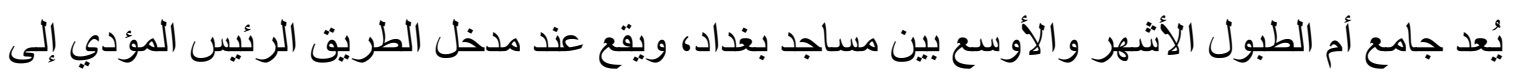
مطار بغداد الدولي، وتبلغ مساحته حوالي 15000 متر مربع ويستوعب نحو 1500 مصلٍِ، وقد اكتمل بناؤه عام 1968. و اطلق عليه اسم أم الطبول نسبة إلى الأرض التي شئ شيد عليها، و التي كانت تحمل الاسم 
نفسه منذ عهد الملكية، وكانت ساحة لتدريب أفر اد الجيش على الرماية، مكانها خارج بغداد وقتذالك، و عند

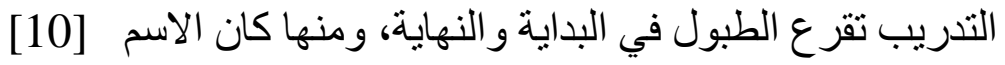

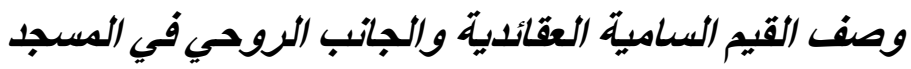

أولا / الثوابت اليقينية

ابراز عظمة المثل : يتميز المسجد بكونه مهيمن بصريا وشكليا ضمن السياق المجاور له بالإضافة الى انه يعطي الإحساس بالعظمة والهيية و الوقار وهي من ابراز سمات السمو ، كما انه يحمل تفردا شكليا

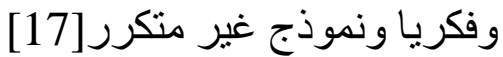
ديمومة الخلود : يرتبط بناء المسجد بحدث تاريخي حيث كان الموقع يستخدم ميداناً وساحة للرمي

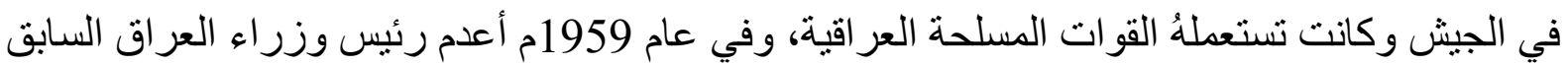

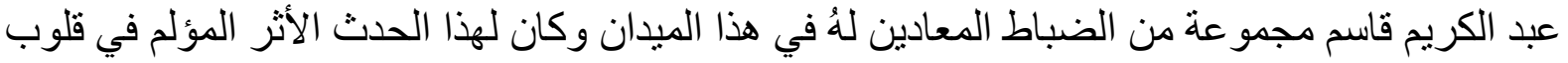
و نفوس العر اقيين وبعد حركة 8 شباط 1963 و الإطاحة بنظام عبد الكريم قاسم وجماعته، تم إنشاء هذا

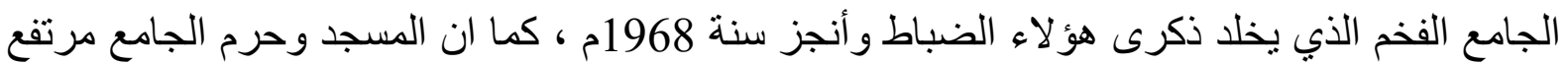

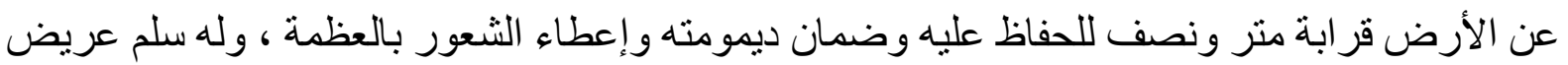

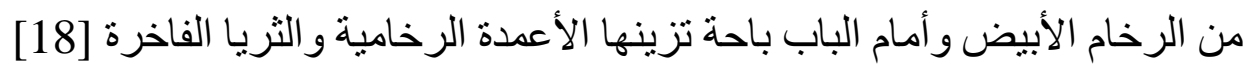

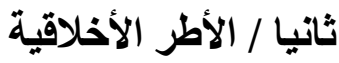
الرمزية : يتعامل المسجد مع مبادئ الإسلام والتي تتص على التهائ التفاع المبنى عن ما يحيطه بالإضافة

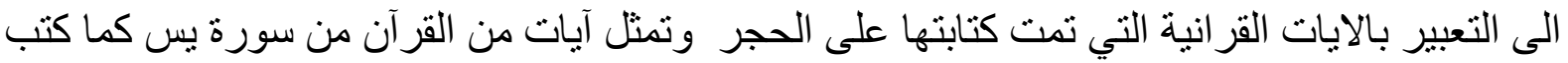
داخل الحرم آيات من سورة الرحمن وآية الكرسي والتي تعطي روحية عالية للمكان وترتبط بقيم أخلاقية

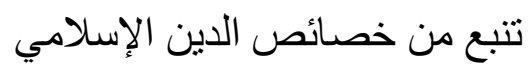
ابراز الهوية: من خلال التعبير عن كل تفاصيل المسجد و اعطاءها الخصوصية المرتبطة بكل فضاء

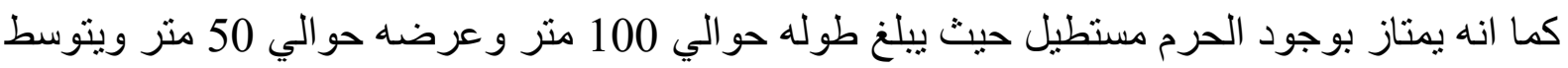

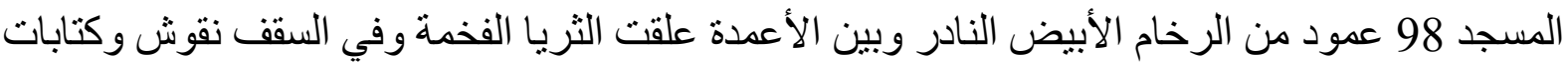
بديعة نقتت بأيدي عمال من مصر ماهرين في هذا الفن. و التي تعزز من هوية هذا المسجد وتكسبه سموا عقائديا[3]. ثالثا / القيم الإنساتية استثارة القيم المعنوية : يرتبط المسجد بالعديد من المعاني والتي تجعل الافر اد يرتبطون بذكريات

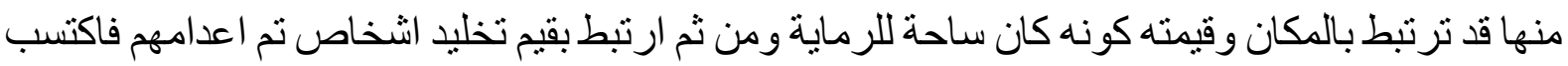
معنى روحيا اخر يجعل منه دائم الحضور في الذاكرة الجمعية بالإضافة الى القيم التي يملكها الجامع في اثارة مشاعر العظمة و الجلال و السكينة و الطمانينة الارتباطات البصرية : يمثل هذا المسجد معلما مميزا في بغداد والعراق وهو رهئو رمز الدينيا وسياسيا بالإضافة الى القيمة الاجتماعية التي يضفيها وجوده في تعزيز المكان من حيث ارتباط الافر اد فيه و وإقامة الصلاة كما انه مميز بصريا من كل المحاور الحركية والبصرية الممتدة حوله مما يشكل نقطة جاذبة وهية ومعلما مهما في المكان [19]. كما في الثكل فئل 2 
مبادئ السمو الابستمولوجي العقائدي

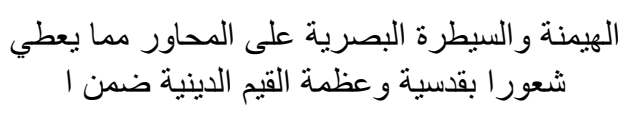

الهيمنة والسبطرة البصرية على المحاور مما بعطي

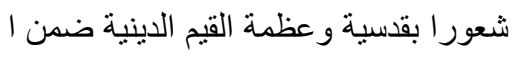

تفرد المسجد شكليا وبصريا وفكريا ضمن سياقه

قيمة المسجد الدينية والتي تجعل الافر اد يقيمون

الصلاة وأداء العبادات المختلفة و قيمته الرئه الروحية

قدسية المسجد بالإضافة الى فكرة التخليد للأشخاص بالإضافة الى ديمومة المو اد المبني منها لئن
ابراز عظمة المثل المنسامية (نتاج برتبط بالمثل المتسامية)

هوية متفردة ماديا ومعنويا (تفرد شكلي -بصري - رمزية النتاج )

استثارة القيم الروحية اللامتتاهية (نتاجات ذات قدسية و عقائدية )

ديمومة الخلود الزمني و المكاني (القدرة على استمر ارية الحضور الفاعل

الثكل 2: يوضح مبادئ السمو الابستمولوجية المتحققة في الجامع ، المصدر الباحث

\section{نصب الثهبي في بغداد}

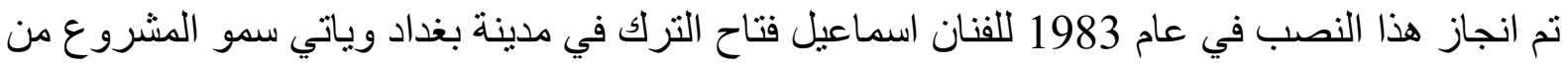

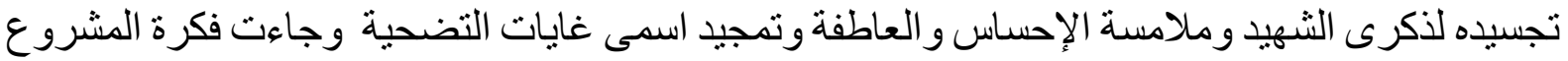

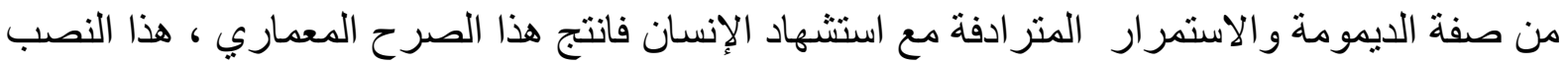

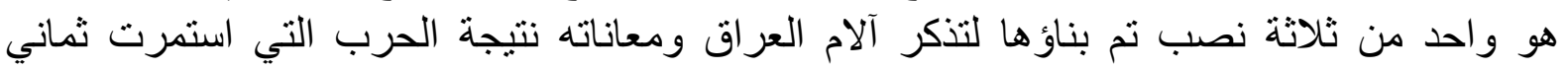

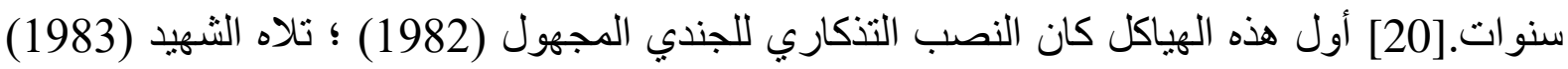

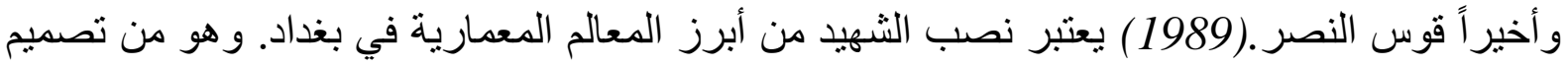

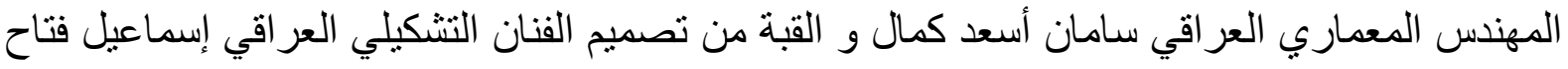

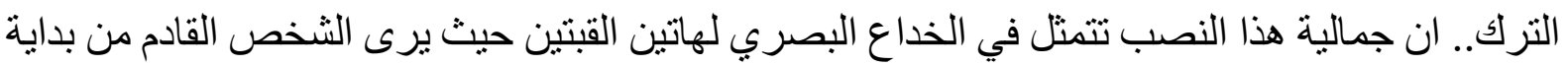

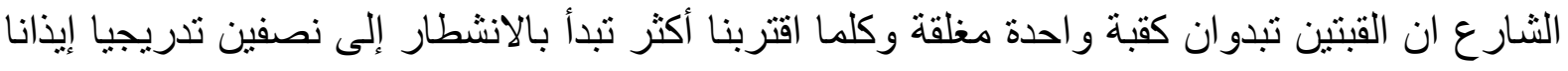

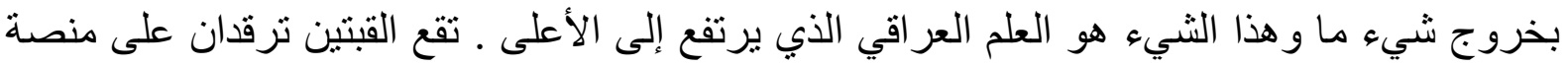

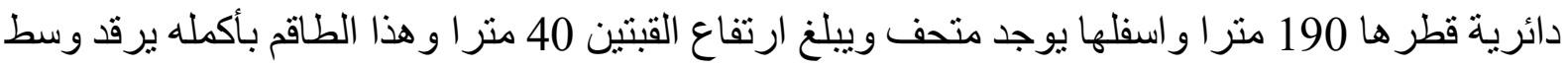

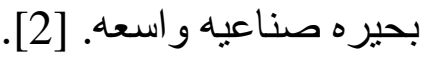
وصف القيم السامية العقائدية والجانب الروحي في الرئة المسجد أولا / الثوابت اليقينية

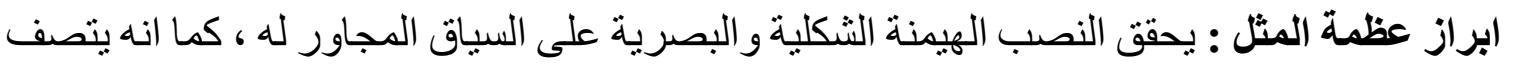

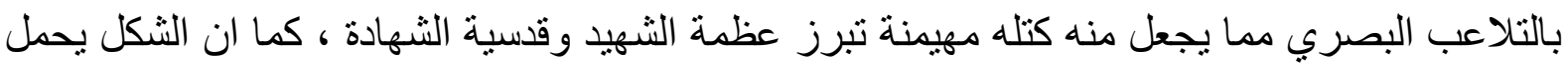

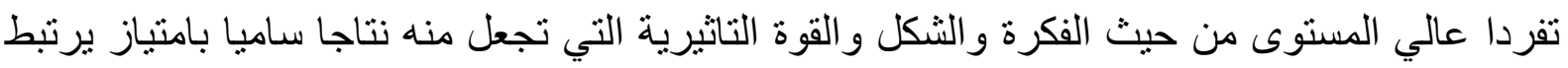

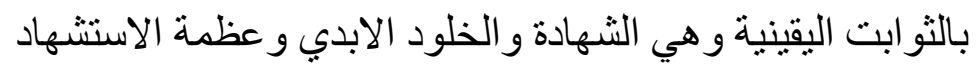

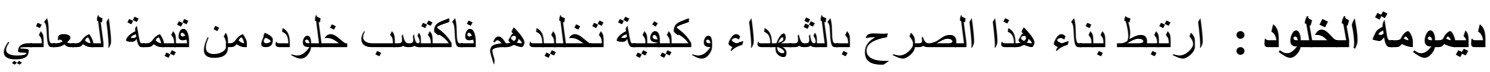

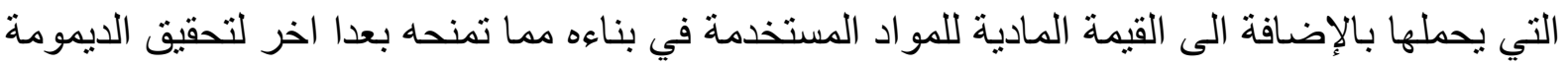

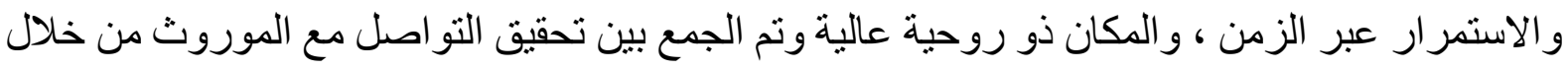

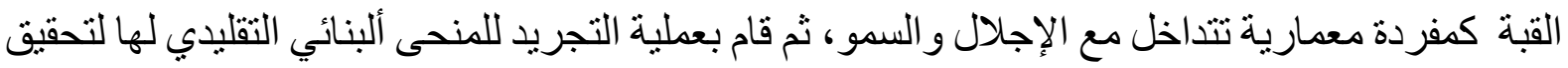

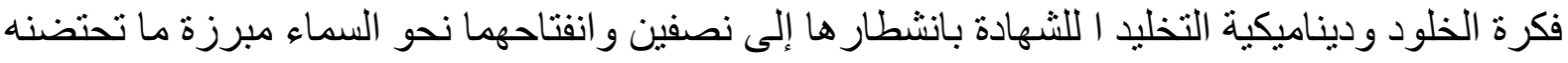

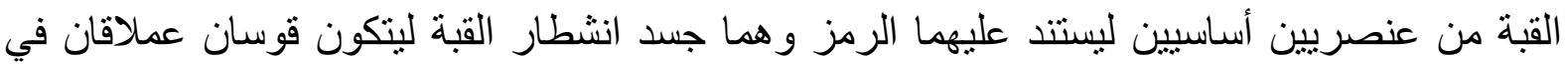

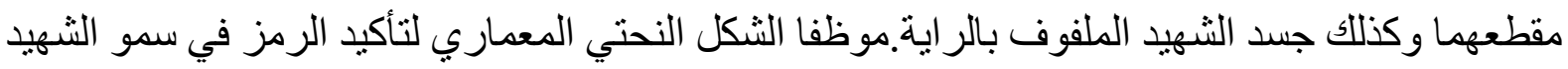


ثانيا / الأطر الأخلاقية

الرمزية : تم استخدام الرموز الدينية والمجتمعية المتعارف عليها و التي تحمل قدسية عالية وارتباطها

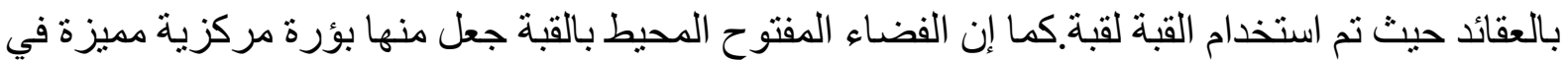

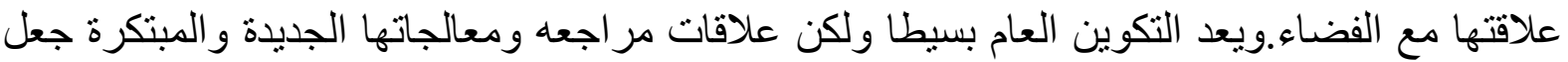

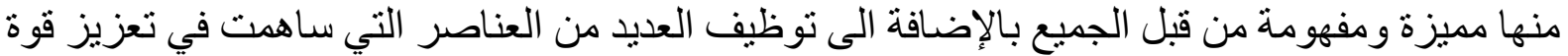

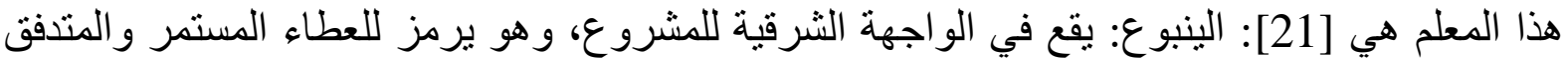

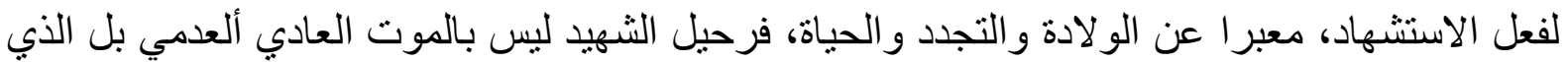

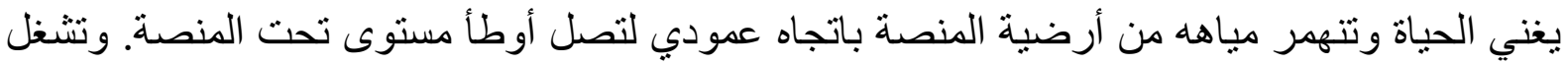

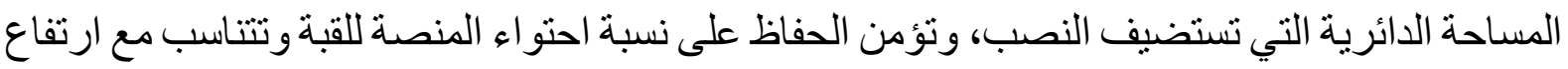

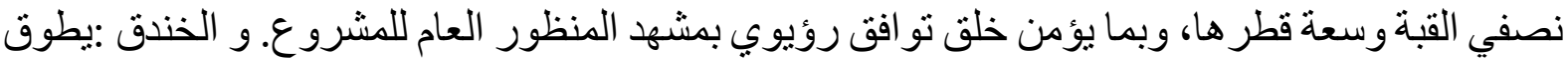

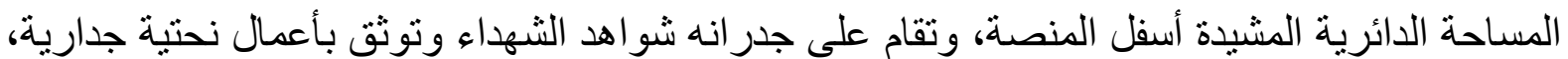

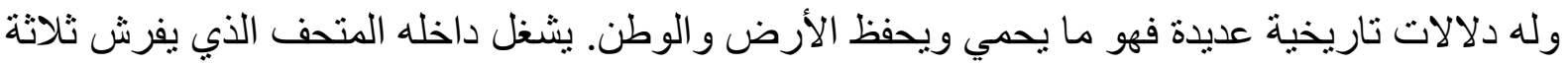

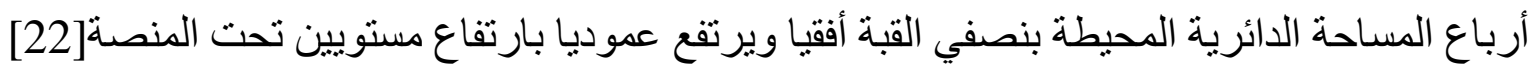

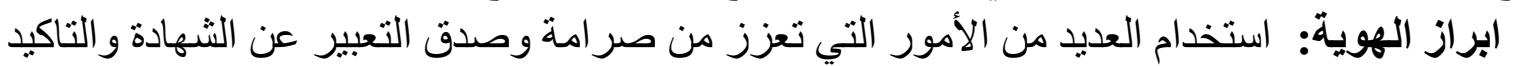

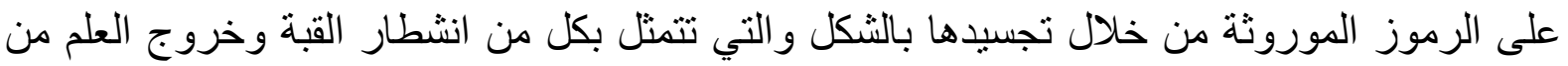

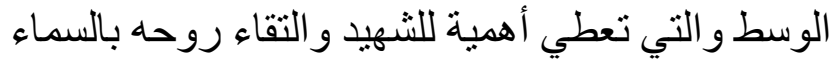
ثالثا / القيم الإنسانية استثارة القيم المعنوية : يعطي هذا النصب احاسيس مختلفه فهو يجمع بين الإحساس بالقدسية والتعظيم و التمجيد للشهيد بالإضافة الى الإحساس بالرهبة هنية عند الاقتراب من النصب و الثُعور بفخامة هذا المعلم

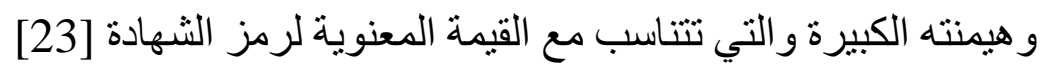

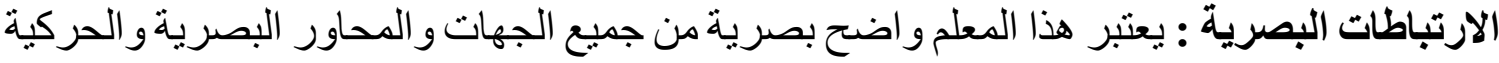

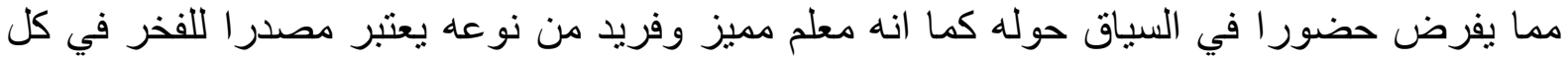

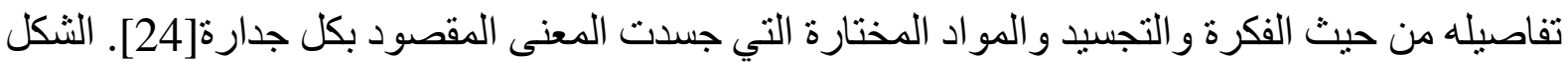
رقم 3.

\section{مبادئ السمو الابستمولوجي العقائدي}

\begin{tabular}{|c|c|}
\hline 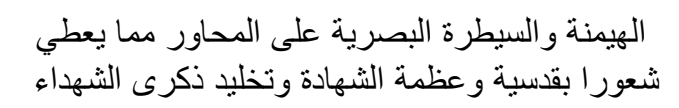 & ابر از عظمة المثل المتسامية (نتاج يرتبط بالمثل المتسامية) \\
\hline تفرد النصب شكليا وبصريا وفكريا ضمن سياقه & هوية متفردة ماديا ومعنويا (تفرد شكلي -بصري - رمزية النتاج ) \\
\hline 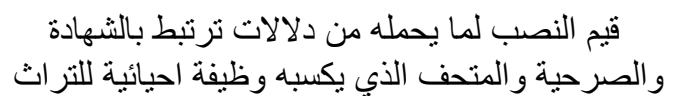 & استثارة القيم الروحية اللامتتاهية (نتاجات ذات قدسية وعقائدية ) \\
\hline يرتبط بفكرة الخلود وديمومة الحياة بعد الثهادة وقدسية & ديمومة الخلود الزمني و المكاني (القدرة على استمر ارية الحضور الفاعل \\
\hline
\end{tabular}

الثكل3: يوضح مبادئ السمو الابستمولوجي المتحققة في نصب الثهيد ، المصدر الباحث 


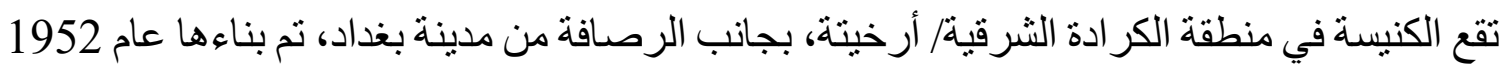

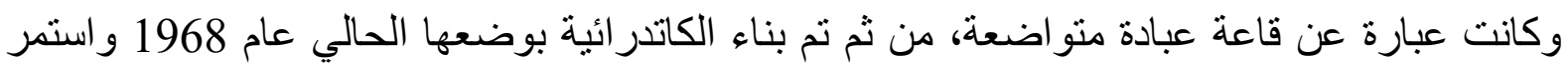

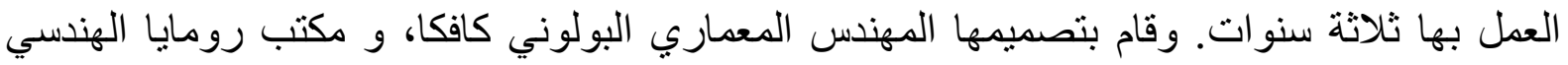

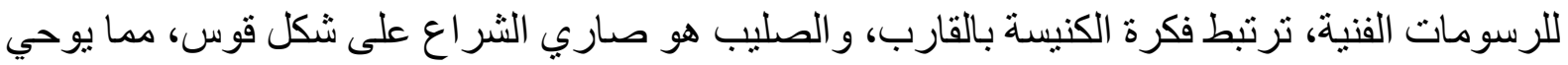

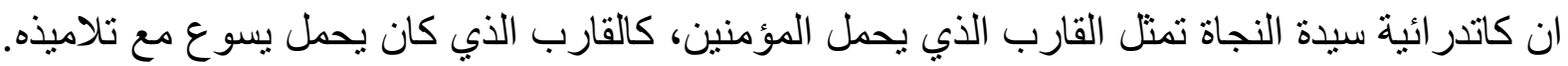

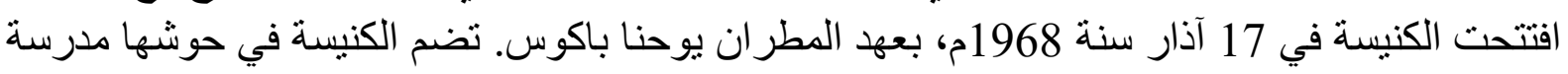

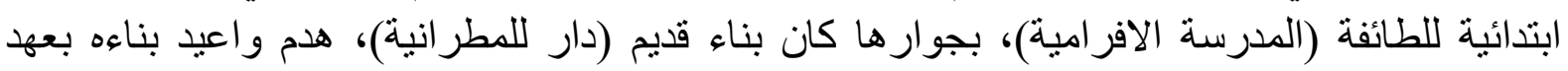

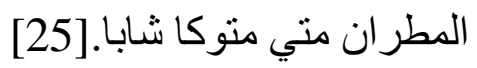
وصف القيم السامية العقائدية والجانب الرواني الروحي في المسجد أولا / الثوابت اليقينية

ابراز عظمة المثل : تهيمن الكنيسة شكليا من حيث الاختلاف و التفرد الذي يعطيها تميز الفئ عن غيرها

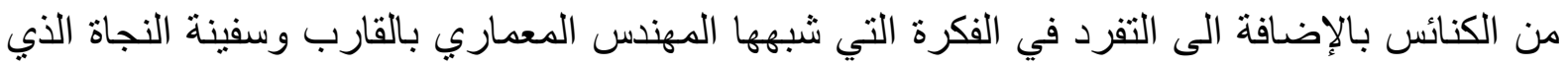

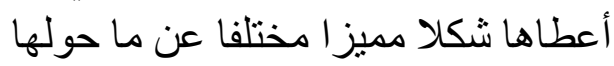

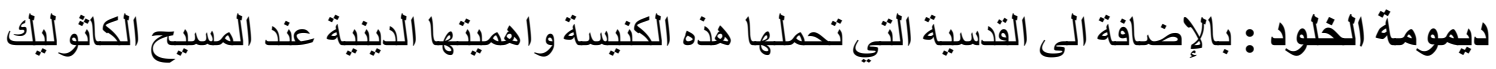

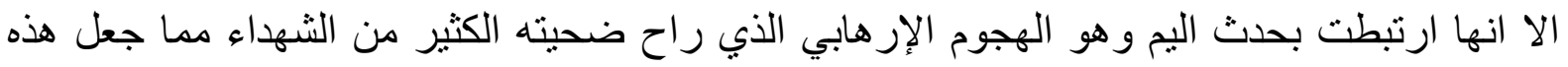

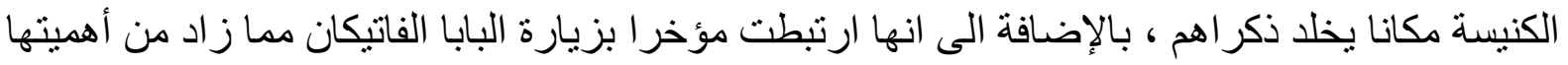

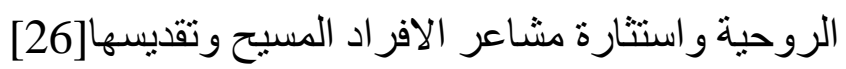
ثنانيا / الأطر الأخلاقية الرمزية : تتميز هذه الكنيسة بالمدخل المشابه للقارب والارتفاع ضمن المناب السياق مما يمكن تمييزها

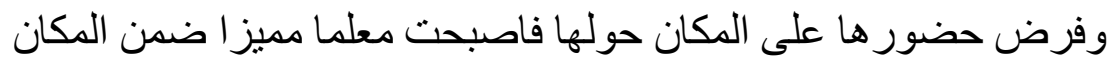

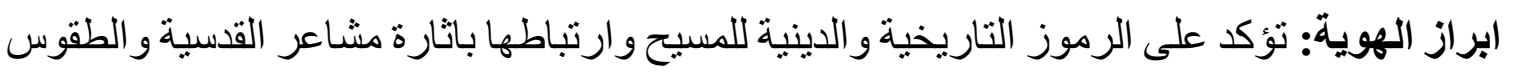

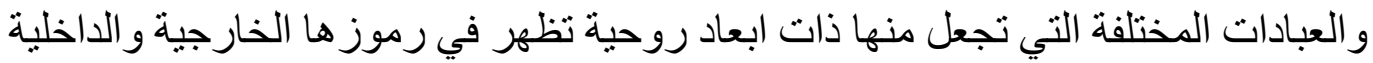
ثالثا / القيم الإنسانية

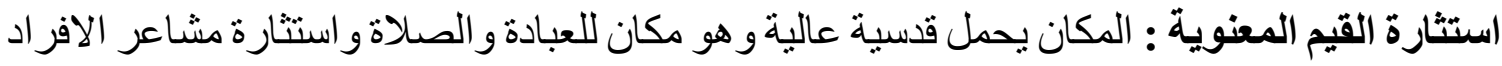

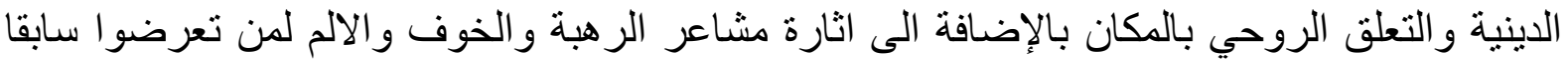

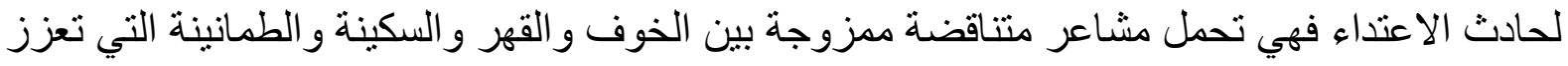

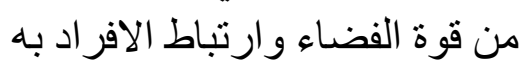

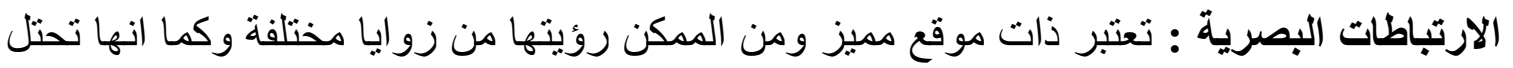

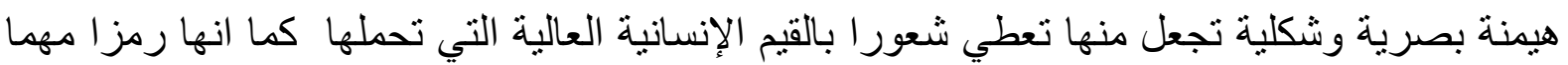
للايانة الكانوليكية من حيث أهيتها وقديتها بالإضافة الى انها معلما حضاريا للمدينة ككل [27]. الاستثتاجات

ظهر في هذا البحث العديد من النتائج اتضح من خلالها:

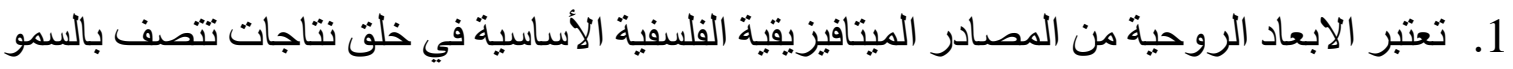
كونها تمثل ماوراء الزمان ولاتنطبق عليها التغيرات او التحو لات ويكون ثابت الفكر و العقيدة

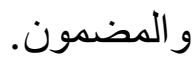


2. تؤثر الابعاد الروحية تاثير ات يقينية في حياة الافر اد من خلال فرض معتقدات وفلسفات ورؤى

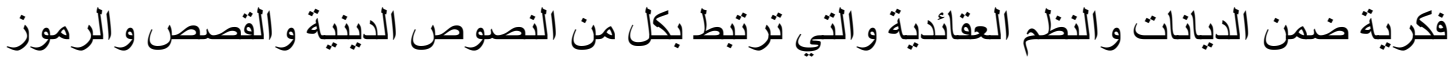
الدينية و الموروثات التر اثية و المقدسات. 3. يرتبط المنهج الإبستمولوجي العقائدي بفهم الأمور الغيبية و الدينية والثرائع المقدة التي تساير مقتضيات الإنسان. 4. الابستمولوجيا العقائدية ترتبط بالقيم الروحية وتتجاوز كل الإبستمولوجيات السائدة وهي رؤية توحيدية لعقل الإنسان في تعامله الدؤوب بين ثلاثية مطلقة، هي الغيب و الإنسان و الطبيعة .

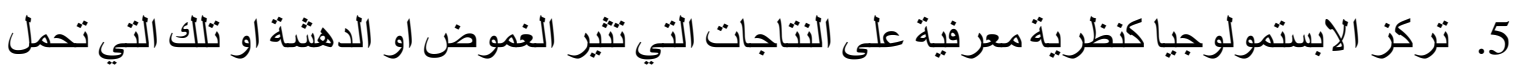

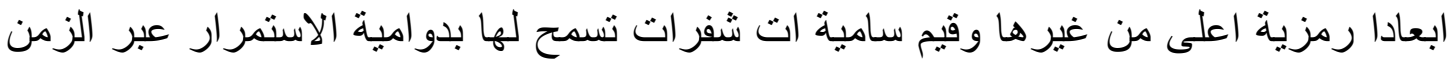

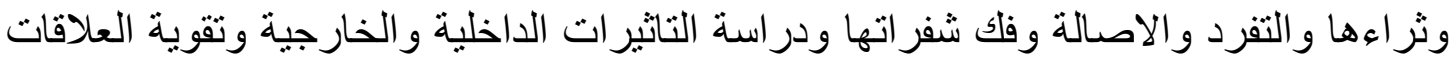
الاجتماعية بالمجتمع ، فتقوم الابستمولوجيا بفك شفراتها من خلال البحث عن استحداث بنية مفاهيمية عالية المستوى الفكري و الادائي و الثكلي للنتاجات التي تتصف بالسمو ودئ ودور هذه الابعاد الروحية في خلق السمو العقائدي. 6. يمثل السمو الحد الممزوج بين الأناقة الدينية و العلمانية المعاصرة وهو دلالة للتعبير عن ثقافة الشعوب من خلال عمث التجارب و البحث عن الأصول و التحليل الذاتي و النفسي. 7. يشير السمو العقائدي الى كل ماهو مفارق ومتعالي لحياة الناس الدنيوية ويرتبط به الافر اد ارتباطا

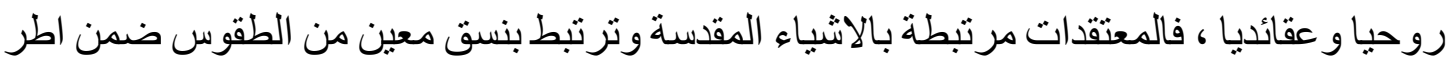
معينة تختلف من وجهة الى أخرى. 8. ترتبط العقائد بحقائق ويقينيات مختلفة تمنح النتاج صفة السمو العقائدي الذي يجعلها ترتبط بالجو انب الروحية مما يمنحها صفة الدو ام و البقاء ويعطيها قوة وقدرة عظيمة ترتبط أحيانا بالر هبة و الخوف. 9. السمو الابستمولوجي العقائدي يرتبط بوجود ثو ابت يقينية ذات ابعاد روحية عالية في النتاج والتي

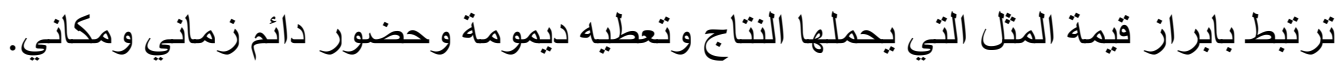

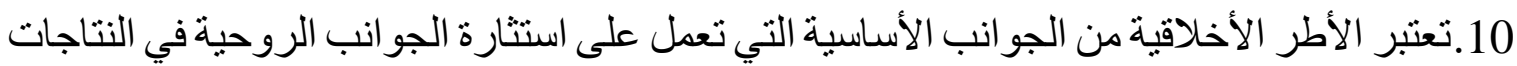
التي تتصف بالسمو العقائدي من خلال الرموز المستخدمة وإبراز هوية ثقافية ودينية ترتبط

$$
\text { بالمجتمع. }
$$

11.وجود القيم الإنسانية و استثارة القيم المعنوية المرتبطة بالاحساس بالر هبة والخوف او التعاطف

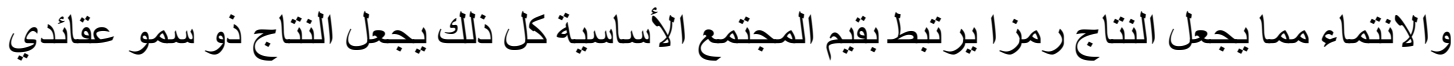

$$
\text { يعزز من قيمة المكان و السياق حوله. }
$$

المصادر

1. ب. جمال, “|بستمولوجيا بانشلار بين الفلسفة و العلم,"/الاكاديمية للاراسات الاجتماعية و الانسانية vol. 11, no. 1, pp. 155-163, 2019.

2. إ. رزوق and ن. محمود, “، الإبسـتمولوجيا و علاقتها بعلم النفس.2015. Tishreen Univ. Journal-Arts Humanit Sci. Ser., vol. 37, no. 5, 2015.

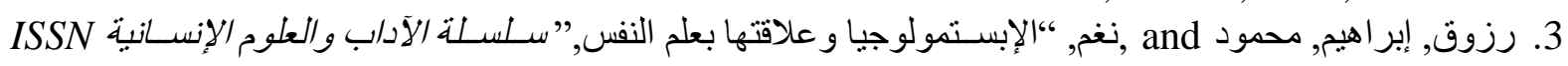
2079-3049, vol. 37, no. 5, 2016. 4. ب. هلال, “،التأويل في الفلسـفة الحديثة و المعاصــرة ومنطق التعامل مع إبهام المقدس الديني من منظور بول ريكور, ”, 
5. S. L. Farhan, V. S. Akef, and Z. Nasar, "Revitalizing the historical center of Al-Najaf city in Iraq: learning from the British conservation experiences," J. Cult. Herit. Manag. Sustain. Dev., vol. ahead-of-p, no. ahead-of-print, Jan. 2021.

6. A. Helles, "The Metaphysical and Symbolic Meanings of Islamic Decoration-towards New Approaches to Revitalize Islamic Architecture," J. Art Archit. Res. LONAARD, vol. 5, 2011.

7. H. S. O. Adelphi, S. L. Farhan, and H. A. H. Alshamari, "The Threshold of Urban Sustainability within the Traditional Cities: Traditional Alnajaf city as a case study," \{IOP\} Conf. Ser. Mater. Sci. Eng., vol. 1058, no. 1, p. 12055, Feb. 2021.

8. K. Harries, The ethical function of architecture. mit press, 1998.

9. A. N. Sabeeh Lafta Farhan, Ihsan Abbass Jasim, "Urban sustainability in Old City Centres, a Comparison Between the City of Najaf in Iraq and Italian Cities Experiences," no. 12, 2016.

10. I. A. Jasim, S. L. Farhan, and H. M. Hasan, "Ways to Activate Urban Transport to Achieve Urban Sustainability,” IOP Conf. Ser. Mater. Sci. Eng., vol. 1090, no. 1, p. 012034, 2021.

11. K. G. Rasheed and S. M. A. Hamza, “أثر المواقع المقسة في خصوصية المدينة," Iraqi J. Archit. Plan., vol. 15, no. 1, 2016.

12. B. Olsen, Sacred places around the world: 108 destinations. CCC Publishing, 2004.

13. I. Abbass Jasim, S. Lafta Farhan, and S. AL-MAMOORI, "Smart Government: Analysis of Shift Methods in Municipal Services Delivery: The Study Area: Al-Kut - Iraq," J. Univ. Kerbala, vol. 15, no. 3, p. 2017, 2017.

14. R. B. Marks, China: An environmental history. Rowman \\& Littlefield, 2017.

15. M. Elvin, "The environmental legacy of imperial China," China Q., vol. 156, pp. 733756, 1998.

16. R. Selden, P. Widdowson, and P. Brooker, A reader's guide to contemporary literary theory. Routledge, 2013.

17. S. Farhan and M. G. Abdelmonem, "Navigating the socio-spatial and planning conditions of traditional public spaces in Iraq's holy cities," in Traditional Dwellings and Settlements Review, 2018, vol. 30, no. 1, p. 81.

18. S. L. Farhan, H. I. Alyasari, V. S. Akef, S. L. Zubaidi, and K. S. Hashim, "Analysing the Transformed Urban Patterns of Al-Najaf Historical Center: Urgent Issues and Possible Solutions," IOP Conf. Ser. Mater. Sci. Eng., vol. 1058, no. 1, p. 12052, 2021.

19. S. lafta farhan, "Deterioration in the centers of historic towns The case study: the residential environment for the ancient of Kut city," iraqi J. Archit. Plan., vol. 10, no. 3 , pp. 128-148, 2014.

20.S. L. Farhan, "Sustainable neighborhood Comparative Analysis of Al Kut Neighborhoods Sustainable neighborhood Comparative Analysis of Al Kut Neighborhoods," no. December, pp. 302-317, 2018.

21. S. L. Farhan, H. H. Samir, and H. S. Adelphi, "Urban changes and its impact on the tangible and intangible heritage of City's Centre: Najaf City as a Case Study," IOP Conf. Ser. Mater. Sci. Eng., vol. 1058, no. 1, p. 12070, 2021.

22. M. R. Hagerty, “Testing Maslow's hierarchy of needs: National quality-of-life across time," Soc. Indic. Res., vol. 46, no. 3, pp. 249-271, 1999. 
23. I. A. Jasim, S. L. Farhan, L. A. Al-Maliki, and S. K. AL-Mamoori, "Climatic Treatments for Housing in the Traditional Holy Cities: A Comparison between Najaf and Yazd Cities," \{IOP\} Conf. Ser. Earth Environ. Sci., vol. 754, no. 1, p. 12017, Apr. 2021.

24. H. A. et al. S. Farhan, T.Mutas, "Digital Era Influence on Neighbourhood Planning," I O P Conf. Sci. Mater., 2021.

25. S. L. Farhan, "Effect of New Urban Transformations at Townscape of Historical Cities Urban Study of Alnajaf Hist,” J. Eng., vol. 23, no. December, pp. 1-20, 2018.

26. S. L. Farhan, H. I. Alyasari, H. H. Samir, S. L. Zubaidi, and K. S. Hashim, "Conservation Approach as an Architectural Instrument to reviving Historical Cities; technical analysis for multi international cases," IOP Conf. Ser. Mater. Sci. Eng., vol. 1058, no. 1, p. 12071, 2021.

27. Z. A. ; Farhan, Sabeeh Lafta 1 ; Nasar, "Urban identity in the holy cities of Iraq: Analysis trends of architectural designers in the city of Karbala," J. Urban Regen. Renew., vol. 14 Number, no. 2020, pp. 210-222(13), 2020. 